\title{
FRÜHMITTELALTERLICHE BURGWÄLLE DES EHEMALIGEN KREISES MILITSCH-TRACHENBERG IM LICHTE DER ARCHIVALISCHEN UND KARTOGRAPHISCHEN QUELLEN VOM 16. BIS ZUM BEGINN DES 20. JAHRHUNDERTS
}

\author{
EARLY MEDIEVAL STRONGHOLD RELICS OF THE FORMER \\ MILICZ-ŻMIGRÓD DISTRICT IN THE LIGHT OF ARCHIVAL AND CARTOGRAPHIC \\ SOURCES FROM THE $16^{\mathrm{TH}}$ TO THE EARLY $20^{\mathrm{TH}}$ CENTURY
}

\begin{abstract}
The paper discusses changes in the way early medieval stronghold relics located in the North-East Silesia were perceived during the past four centuries and shows how the interest in these structures were developing from the early modern period until the turn of the $20^{\text {th }}$ century. The aforementioned issues were not studied in a detailed way until now. Written historical records, cartographic sources together with the toponymy as well as the typology of the studied structures that had developed since the $19^{\text {th }}$ century were analysed. Special attention was paid to the stronghold relics in Wrocławice, Lelików, Góry and Milicz. They make up a part of a bigger settlement complex located within the area of the former Milicz-Żmigród district. The paper goes beyond the previous studies which aimed chiefly at recording archaeological sites (creating a complete catalogue) and focuses on a critical approach towards the issue of evolution in methods of documenting strongholds over time.
\end{abstract}

KEY WORDS: early medieval stronghold relics, the Valley of Barycz river, cartography, antiquarianism, archival sources, Milicz

\section{EINLEITUNG}

Die Kataloge der frühmittelalterlichen Burgwälle (slawische Burgwälle) scheinen zwar beinahe komplett zu sein, es gibt jedoch immer noch Gebiete, für welche man sich des Vorhandenseins derartiger Bauten relativ spät, denn erst zur Wende zum zweiten Viertel des 20. Jh., bewusst wurde und deren wissenschaftliche Erkennung weiterhin unzureichend bleibt. Ein solches Gebiet ist der ehemalige Kreis Militsch-Trachenberg (poln. Milicz-
Żmigród), wo eine systematische Identifizierung und Dokumentation derartiger Funde erst in den 30er Jahren des vorigen Jahrhunderts stattfand.

Eine Entwicklungsanalyse sowie Charakteristik der frühmittelalterlichen Besiedlung auf diesem westlich der Oder gelegenen Gelände ist äußerst schwierig, denn dessen Topographie unterlag häufiger Umgestaltungen infolge natürlicher oder anthropogener Veränderungen von Flussläufen sowie 
der auf Fischzucht basierenden, den Bau von künstlichen Teichen erzwingenden Wirtschaft. Diesen Sachverhalt komplizieren überdies relativ häufig - vor wie nach dem Jahr 1945 - Änderungen der Orts- und Flurnamen, die in der Folge unklare Lagebezeichnungen der archäologischen Fundstellen mit sich brachten. Einige davon, die in der älteren Literatur erwähnt wurden, wie zum Beispiel in Kraschnitz-Hammer (poln. Krośnice) und Melochwitz (poln. Miłochowice), können heutzutage im Gelände nicht nachgewiesen werden. Ein krasses Beispiel für die daher sich ergebenden Missverständnisse ist die Lage eines frühmittelalterlichen Burgwalls nördlich des Dorfs Klein Ossig (poln. Mały Osiek). Von dem Burgwall, der mit diesem Dorf oder Vorwerk, das in unterschiedlicher Zeit die Namen Jamnigk (poln. Jamnik) oder Radziunz (poln. Radziąc) trug, zusammenhing, ist in den Quellen ab der zweiten Hälfte des 19. Jh. die Rede. Beide Siedlungen sind jedoch so weit voneinander entfernt, dass man das Bestehen von zwei Fundstellen zulassen soll, von denen uns nur einer bekannt ist. Demnach stellen sich die Fragen zur Wahl von möglichst effizienten Methoden der Bewertung von Archivangaben, die gegenwärtig unter anderen unter invasionslosen Forschungsmethoden gesucht werden.

Die Einsetzung invasionsloser Forschungsmethoden findet in der Archäologie in den letzten Jahren immer häufiger statt. Darunter versteht man Luftbilder, oberflächliche und geophysikalische Prospektionen sowie Luft Scannen der Erdoberfläche - Light Detection and Ranging. Dadurch konnte eine viel genauere Beobachtung des Geländereliefs und somit - ein präziseres Abbild und die Analyse der Topographie von untersuchtem Gelände möglich werden. Die Hypothesen, die aufgrund der Studie der Quellen - mittelalterlicher Diplome, alter Drucke, Kataloge und Karten, sowohl handschriftliche als auch gedruckte Berichte und Notizen von früher geführten Ausgrabungen, der Dokumente, die mit der sachlichen Tätigkeit der Museen und unterschiedlichen Vereinen verbunden waren, sowie der sowohl von Staatsverwaltungsämtern als auch Privatpersonen geführten Korrespondenz - aufgestellt wurden, können mithilfe der LiDAR-Messungen aufs Neue interpretiert werden. Gleichzeitig sollen die durch die modernen Prospektionsmethoden gewonnenen Daten stets den schriftlichen-, kartographischen-, sowie Bildquellen gegenübergestellt werden. Es ist dabei zu betonen, dass der Zugang zu diesen Materialien im letzten Viertel des 20. Jh. durch die immer häufigeren Forschungen der Archäologiegeschichte erleichtert wurde. Eine der ersten komplexen Abhandlung dieser Art für Schlesien ist die Serie von Beiträgen von Janusz Kramarek (Kramarek 1969; 1970; 1971; 1972), die der Geschichte der Altertumskunde und Geburt der vorgeschichtlichen Archäologie der Region gewidmet wurden. Beinahe zehn Jahre später wurden einem breiten Kreis der Interessenten die Angaben zu den im Staatsarchiv und Archäologischen Museum in Breslau aufbewahrten Archivalien zugänglich gemacht (Kramarek, Margas 1980). Zu dieser Zeit erschienen auch gedruckte Zusammenstellungen von schlesischen im 19. und zu Beginn des 20. Jh. entdeckten und verzeichneten Fundstellen (Kokosza 1989; Demidziuk 1999). Für den nördlichen Teil Schlesiens wurden bislang Archivalien bearbeitet, die die ehemaligen Kreise Glogau und Fraustadt betreffen (Demidziuk 2000; 2007).

Diese Ausarbeitungen ermöglichten einen Einblick in den bisherigen Stand der archäologischen Burgwallforschung in dem ehemaligen Kreise Militsch-Trachenberg aus einer neuen Perspektive zu gewinnen und ihn zu bewerten. Deswegen ist es der Mühe wert nochmals die Quellen zu untersuchen, die den Prozess der Erkennung der frühmittelalterlichen Wehrsiedlungen verfolgen lassen. Es ist jedoch keine leichte Aufgabe, denn sie wird durch einen instabilen Begriffsapparat, insbesondere im Bereich der deutschen Forschung, sowie beinahe gänzlichen Austausch des wissenschaftlichen Milieus Schlesiens nach 1945 erschwert. Es ist auch zu betonen, dass die ehemaligen Kreise MilitschTrachenberg, Gurau und Wohlau, das heißt die heutigen Kreise Militsch, Wohlau und Gurau sowie die Gemeinde Trachenberg im Kreis Trebnitz, am Rande des Interesses der deutschen Forscher blieben. Diese deutliche Lücke in der Quellenerkennung und Dokumentation wurde zur Hauptanregung, eine Frage nach Entwicklung des Interesses am lokalen archäologischen Erbe im Gebiet des ehemaligen Kreises Militsch-Trachenberg, wie auch Veränderungen an dessen Identifizierung- und Dokumentierungsmethoden im Laufe der Zeit zu stellen. Wesentlich war dabei die Frage der Glaubwürdigkeit und Nützlichkeit der Archivalien, Altdrucken und frühen altertumsbezogenen Bearbeitungen von diesem Gebiet bei den gegenwärtigen analytischen und synthetischen Forschungen zu erwägen. Günstige Umstände für die Erwägung dieser Problema- 
tik schaffte die Ausführung des Projekts zum Thema Kulturlandschaft und natürliches $U$ mfeld des nord-östlichen $\mathrm{G}$ renzgebiets Schlesiens im frühen
Mittelalter. Fachübergreifendes archäologischumweltbezogenes Studium ausgewählter Wehranlagen ${ }^{1}$.

\section{FORSCHUNGSGEGENSTAND}

Ein direkter Anlass, die im Titel der Abhandlung angesprochene Problematik aufzunehmen, gaben Untersuchungen von vier frühmittelalterlichen Burgwällen von erhaltener, vor Ort erkennbarer Form, die im Gebiet des nordöstlichen Teils vom heutigen Schlesien liegen: in, Breslawitz (poln. Wrocławice), Lelikowe (poln. Lelików), Guhre (poln. Góry) und Militsch (poln. Milicz). Sie bilden einen Teil von einem größeren Siedlungskomplex, der sich im Bereich des ehemaligen Kreises Militsch-Trachenberg befindet (Abb. 1). Die Auswahl der Objekte wurde durch einige für die Erkennung wesentliche Voraussetzungen veranlasst. Die erste davon ergab sich daraus, dass alle Burgwälle dieses Kreises der einteiligen, kleinen, ringförmigen Objektart angehören, die frühmittelalterlicher Herkunft sind. Die zweite - aus dem Erkennungsstand der frühmittelalterlichen Wehrsiedlungen in diesem Gebiet, die bereits seit einigen Jahrzehnten Forschungsgegenstand der Archäologen vom Institut für Archäologie und Ethnologie der Polnischen Akademie für Wissenschaften (PAN) sind. Im Rahmen bisheriger Forschungsarbeiten wurden die frühmittelalterlichen Siedlungskomplexe in Militsch (Leciejewicz 2008; Kolenda 2008) und Kasawe (poln. Kaszowo; Dzieduszycki 1972; Dzieduszycka 1977, 1994) teilweise erforscht. Gleichzeitig erkannten die Forscher aus Großpolen den auch im Militscher Becken gelegenen Burgwall in Topola (poln. Topola Wielka; Studia 1995, 42-45). Die Ausgrabungen auf den Fundstellen in Breslawitz, Lelikowe und Guhre ergaben somit die Möglichkeit, die Besiedlung und die sich im frühen Mittelalter im Gebiet Nordostschlesiens vollziehenden Kulturwandel umfassend zu bearbeiten. Ein weiterer Grund für die Auswahl dieser Burgwälle war ihr relativ guter Erhaltungsstand. Sie waren nach wie vor ziemlich gut im Gelände erkennbar, was dazu führte, dass sie seit über einhundert Jahren nicht nur die Aufmerksamkeit der Historiker, sondern auch zahlreicher Geschichtsliebhaber fesseln. Jene Objekte bildeten oft auch einen wesentlichen Bezugspunkt im Aufwertungsprozess des Kulturraums für die Einheimischen, indem sie Anregung für unterschiedliche Sagen, Mythen und Legenden wurden. Nicht ohne Bedeutung war ebenfalls die Forschungsproblematik der im rechtsufrigen Bartschgebiet liegenden Wehrsiedlung. Heutzutage sind manche Forscher der Meinung, dass kleine, im Tal dieses Flusses oder in dessen nächster Nähe befindliche Burgen (der heutige Bartschlauf weicht von dem im 10. Jh. bedeutend ab), wahrscheinlich die südliche Linie bilden, die das am rechten Flussufer gelegene Siedlungsgebiet abschließt. Das östliche Ende dieser Befestigungen bestimmt die Burg in Wielowieś (Großpolen), das westliche die eine in Zippern vel Zapplau (Bartodzieje). Die neuesten Untersuchungen eines Teils von ihnen be-

1 Das Projekt wurde aus den Mitteln des NCN finanziert, Vertrag Nr. UMO 2011/01/D/HS3/04059. Das Forschungsprogramm setzte sich die Bestimmung von Wechselbeziehungen zwischen der frühmittelalterlichen Kulturlandschaft und der natürlichen Umwelt zum Hauptziel, auf die in dem im Titel genannten Gebiet hingewiesen wird. Im Kreis der Forschungsinteressen fanden sich einige Fragen. Die erste davon galt für die Feststellung von Einwirkungen der natürlichen Umwelt auf die Organisationsweise der Kulturlandschaft. Die so aufgestellte Frage erzwang einen Rekonstruktionsversuch der frühmittelalterlichen natürlichen Umwelt. Eine weitere betraf die Problematik, die mit der Feststellung der Bewertungsregeln der natürlichen Landschaft von der damaligen Bevölkerung verbunden war. Ein letztes im Projekt realisiertes Forschungsthema war der Versuch, die in der natürlichen Umwelt unter Einwirkung der siedlungs-wirtschaftlichen menschlichen Aktivität stattfindenden Änderungen wieder herzustellen, mit besonderer Berücksichtigung von Art, Stärke und Richtung des Anthropodrucks. Die Untersuchungen umfassten frühmittelalterliche archäologische Fundstellen, die in den Orten Militsch, Breslawitz, Lelikowe und Guhre im nordöstlichen Teil Schlesiens liegen. Somit konzentrierte sich die Aufmerksamkeit der Forscher auf die Fundstellen, die in einem bestimmten Naturmilieu gelegen waren, dessen Hauptbestandteil der Talkessel der Bartsch - eines breitenkreisparallel ost-westlich fließenden rechtsufrigen Nebenflusses der Oder - ist und dessen Unterteile das Militscher Becken und Trachenberger Becken bilden. Das Bartschgebiet liegt im Bereich der zwei Regionen: Südgroßpolens (rechtsufriges nördliches Flussgebiet) und Nordschlesiens (linksufriges südliches Flussgebiet). 


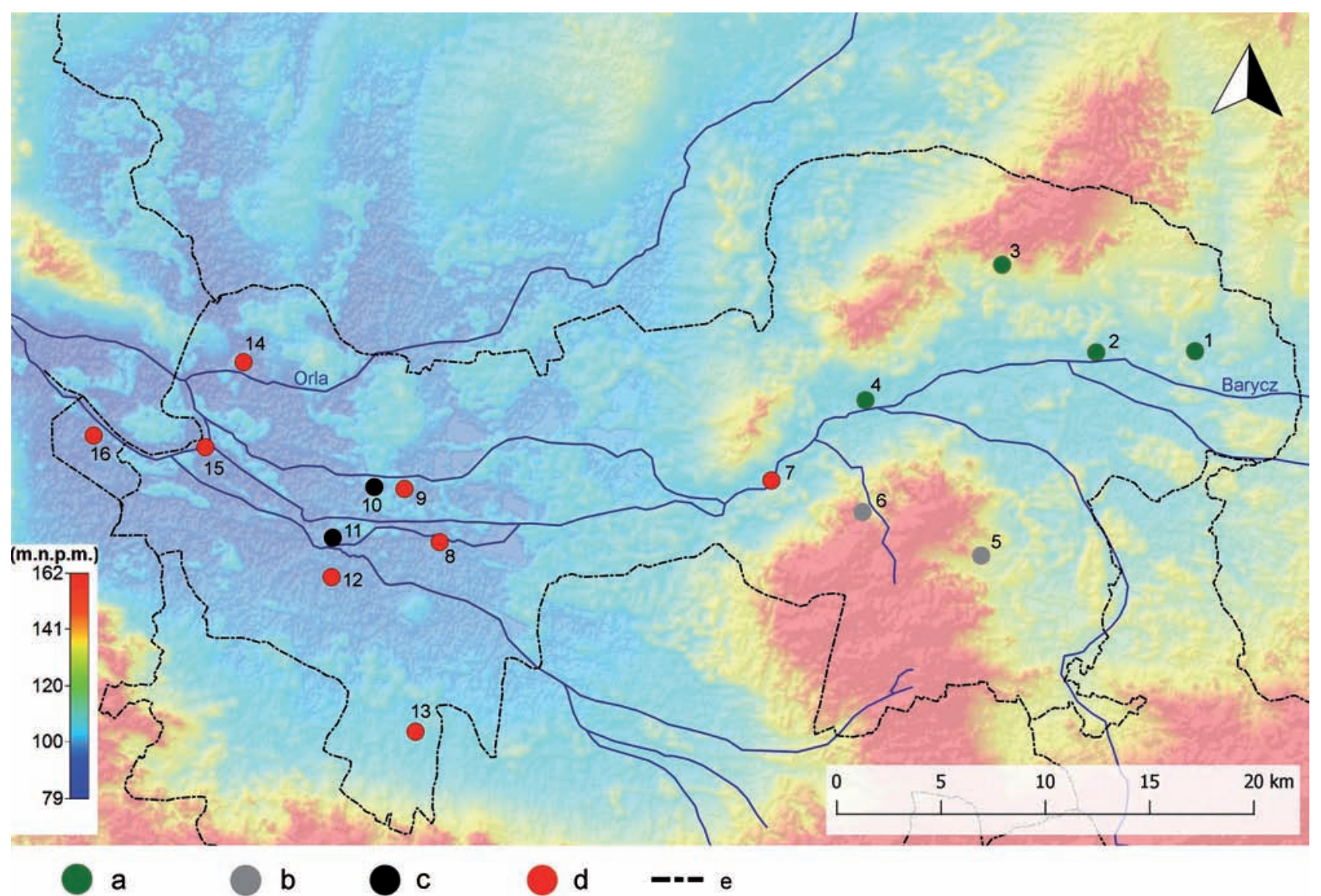

Abb. 1. Lage der archäologischen Fundstellen im Bereich des ehemaligen Kreises Militsch-Trachenberg: a - im Projekt erfasste Burgwälle; b - in der Literatur des 19. Jh. vorhandene Burgwälle, zurzeit im Gelände unerkennbar; c - vermutene Burgwälle, in der Kartei der Burgwälle von M. Hellmich verzeichnet, zurzeit im Gelände nicht erkennbar; d - gegenwärtig bekannte Burgwälle aus dem Gebiet des ehemaligen Kreises

Militsch-Trachenberg; e - Grenzen des Kreises Militsch-Trachenberg; bearbeitet von G. Kiarszys

Fig. 1. Situation of archaeological sites in the area of the former Militsch-Trachenberg District: a - strongholds included in the project; $\mathrm{b}$ - strongholds known from the $19^{\text {th }}$ century literature, presently not visible in the landscape; c-hypothetical strongholds recorded in the M. Hellmich's stronghold index, presently not visible in the landscape; $\mathrm{d}$ - presently known strongholds from the area of the former Militsch-Trachenberg District; prepared by G. Kiarszys

1 - Breslawitz/Wrocławice, 2 - Lelikowe/Lelików, 3 - Guhre/Góry, 4 - Militsch/Milicz, 5 - Kraschnitz Hammer/Kuźnia Krośnicka, 6 - Melochwitz/Miłochowice, 7 - Kasawe/Kaszowo, 8 - Klein Ossig/Mały Osiek, 9 - Schmiegrode/Żmigródek I,

10 - Schmiegrode/Żmigródek II, 11 - Schmiegrode/Żmigródek III, 12 - Trachenberg/Żmigród, 13 - Klein

Peterwitz/Pietrowice Małe, 14 - Korsenz/Korzeńsko, 15 - Kendzie/Kędzie, 16 - Leubel/Lubiel

weisen, dass die Bauaktivitäten daran um die Mitte des 10. Jh. und danach geführt wurden (Kolenda 2011). Nach Zofia Kurnatowska ist dieser Prozess mit der Einverleibung dieses Gebiets vom ersten historischen Herrscher Polens Mieszko I. verbunden. Die Forscherin stellte die Hypothese auf, nach welcher die Burgen belegen ....Errichtung von einer Art Siedlungsbrücke, aber auch eines Netzes von den in Richtung Schlesien gewendeten Militärpunkte. Diese Handlung ging 10-20 J ahr dem Anschluss Schlesiens an den Staat der ersten Piasten voraus. Dies kann auch die von M ieszko I. geplante Erweiterung des Staates, darunter auch die Ab- sicht, Schlesien an den G nesener Staat fest anzuschließen, bezeugen (Kurnatowska 2000, 17-19). Es wird angenommen, dass diese kleinen Burgen um die Mitte des 11. Jh., in der Krisenzeit der ersten Piastenmonarchie, zerstört wurden und danach wurde das siedlungsgeographisch-kulturelle Bild des Bartschgebiets infolge der Reorganisierung des Piastenstaates von Kasimir dem Erneuerer und seinem Sohn Boleslaw dem Kühnen völlig verändert. Unter den neuen Umständen spielte die wieder aufgebaute Burg in Militsch die Hauptrolle, die zum Zentralpunkt der zur schlesischen Provinz gehörenden Kastellanei wurde. Der Entschluss, diesen Ort 
wieder zu beleben, ergab sich wahrscheinlich aus dessen strategischer Lage: in der Nähe einer Furt und an der Strecke eines von Süden nach Norden verlaufenden überregionalen Landwegs. Der Niedergang der Burg fiel vermutlich auf die Wende zum Spätmittelalter und wahrscheinlich wurde sie in der Neuzeit in ein landwirtschaftliches Gebiet umgewandelt, was teilweise die Dekonstruktion ihrer Form mit sich brachte. Die anderen kleinen, verlassenen und mit der Zeit völlig vergessenen Vesten, auf den sandigen Werdern im Bartschtal oder in der direkten Nähe des Flusses gelegen, wurden landwirtschaftlich wegen sumpfigen Bodens nicht genutzt, wodurch sie in relativ gutem Erhaltungszustand geblieben sind.

Im Lichte der vorgestellten Forschungsproblematik und insbesondere im Zusammenhang mit der bereits genannten Lücke im Bearbeitungsstand der Quellen und Dokumentation der frühmittelalterlichen Burgwälle vom angesprochenen Gebiet entstehen grundsätzliche Fragen danach, wann das Interesse an den sich hier befindenden Wehrobjekten erwachsen ist und wie es sich entwickelt hat, wie auch spiegelt dieses Interesse für diesen Teil Europas spezifische Trends wider, oder verfügt es über seinen eigenen Entwicklungsfaden.

\section{FORSCHUNGSMETHODE}

Bei der Zusammentragung der Dokumentation für die Burgwälle in den Ortschaften Breslawitz, Guhre und Militsch sowie des mit ihnen verbundenen Siedlungsumfeldes wurde eine Archivrecherche im Archäologischen Museum Breslau ${ }^{2}$ (zurzeit Abteilung des Museums der Stadt Breslau) durchgeführt. In der dortigen Abteilung für Wissenschaftliche Dokumentation werden die von den Kriegshandlungen geretteten Archivalien aufbewahrt, die sich sowohl auf ganze Fundstellen als auch auf einzelne Funde beziehen. Neben dem Aktenarchiv wurden auch das Fotografische Archiv, Fundsammlungen sowie die im Museum erhaltenen Karten erforscht, auf die seit dem Beginn des 20. Jh. die Lage und Zeitstellung ${ }^{3}$ der aufgedeckten archäologischen Funde aufgetragen worden waren. Weitere Untersuchungen wurden im Staatsarchiv in Breslau durchgeführt. In dessen Sammlungen werden hauptsächlich die Dokumentation von den Felduntersuchungen, Beschreibungen von zufällig bei Erdarbeiten oder während landeskundlicher Exkursionen gemachten Funden sowie Berichte über durchgeführte Ausgrabungen aufbewahrt ${ }^{4}$. Diese Sammlungen sind in der Aktengruppe unter dem

2 An dieser Stelle gebührt K. Demidziuk herzlicher Dank für die Hilfe bei Zusammentragung der Angaben.

3 Die Angaben stammen aus Meldungen, die an das Landesamt für Denkmalpflege in Breslau geliefert wurden. Die archäologischen Fundstellen kamen bei unterschiedlichen Erdarbeiten, darunter auch Autobahnenbau, zutage (Kramarek 1971, 237). Der Fundstellentyp wurde auf der Karte mit einer geometrischen Figur, die Zeitstellung dagegen durch Farbe, z. B. Mittelalter mit Violett, markiert.

4 Sowohl Hand- als auch Maschinenschriften.
Namen Provinzialverwaltung von Schlesien ${ }^{5}$ (Signaturen 732-736) enthalten. Die gewonnen Archivquellen wurden mit den Angaben ergänzt, die sowohl der archäologischen und historischen Fachliteratur als auch den populärwissenschaftlichen Veröffentlichungen entstammten.

Eine Vervollständigung der archivalischen und bibliographischen Recherche war eine Analyse von kartographischen Bearbeitungen, die die Karten ab der Mitte des 17. Jh. umfasste. In der genannten Analyse wurden zwei Arten von kartographischen Quellen ausgewertet. Die erste Gruppe bilden Militärkarten Schlesiens, prinzipiell bereits der Vermessungskartographie zugerechnet, die Gegenstand des Interesses eines breiten Kreises der Forscher, Historiker und Geografen ist (Janczak 1976; Wytyczak 1998, 2008; Konias 1995, 2010; Kot 1970). Aufgrund des Erkenntniswerts wurde in die Abhandlung auch die Karte der Herrschaft Trachenberg aus dem Jahr 1676, die das obige Kriterium nicht erfüllt, hineingefügt. In der vorliegenden Ausarbeitung wurden die Fragen übergangen, die sich auf die Problematik der Bewertung des kartographischen Genauigkeitsgrads oder auf die Glaubwürdigkeit einzelner Karten beziehen, also die Fragen, die in den letzten Jahren häufig behandelt wurden und es wurden die in diesem Bereich geltenden Bestimmungen angenommen (Affek 2012; Zachariasz 2012; Łuczak 2015). Somit wurde die Analyse der kartographischen Unterlagen auf eine Suche nach konkreten Objekten, das heißt nach frühmittelalterlichen archäologischen Fundstel-

\footnotetext{
5 Weiter als AP WSPŚ.
} 
len beschränkt, die die polnische Forschung als Burgwälle bezeichnet. Es wurde allein deren Vorhandensein betrachtet, ihre Markierungsweise (Symbolik oder Abbildung erhaltener Form mit Schraffen), die Art der eingesetzten Benennung sowie ihre Dauerhaftigkeit (d.h. Wiederholbarkeit auf nächstfolgenden Karten). Die zwei ersten Eigenschaften können die Erkennung dieser anthropogenen Geländeform durch Augenschein und ihre Identifizierung in der lokalen Landschaft bezeugen. Die auf den Karten zu sehenden Unterschriften, die die Eigennamen derartiger Objekte sind, zeugen von ihrer Deutungsweise, dagegen können die Dauerhaftigkeit der $\mathrm{Na}^{-}$ men, ihre Veränderlichkeit oder völliges Erlöschen das Vorhandensein oder die Verwischung der älteren Tradition belegen. Den zweiten in der Analyse der kartographischen Quellen erfassten Typ bilden die Karten, die die Ergänzung der in der 2. Hälfte des 19. Jh. gefertigten Kataloge oder ältesten Monographien darstellen. Auf den derartigen Karten wurden die Grenzen Schlesiens sowie dessen Wassernetz überwiegend schematisch markiert, solche Informationsebenen wie Topographie, Straßenanordnung oder damalige Verwaltungsgliederungen wurden jedoch übergangen. Eine Ausnahme ist hierbei eine im engen Sinne archäologische Karte von Julius Zimmermann.
Angesichts der Tatsache, dass die Burgwälle in Breslawitz, Lelikowe, Guhre und Militsch ${ }^{6}$ den östlichen Teil des ehemaligen Kreises MilitschTrachenberg bilden, wurden zum Vergleich Objekte desselben Typs im westlichen Teil dieses Gebiets ausgewählt: Kasawe, Klein Ossig, Trachenberg, Schmiegrode (poln. Żmigródek I, II, III), Klein Peterwitz (poln. Pietrowice Małe), Kendzie (poln. Kędzie) und Korsenz (poln. Korzeńsko). Die Grundlage für die Auswahl der Fundstellen bildete der Katalog der Burgwälle der ehemaligen Woiwodschaft Breslau (Mittelschlesien - Anm. des Übersetzers; Kaletynowie, Lodowski 1968), der in seinem Hauptteil mit der von 1903 an aufgebauten, zurzeit im Archäologischen Museum aufbewahrten Kartei der schlesischen Burgwälle von Max Hellmich übereinstimmt (Demidziuk 2014). Weitere Überprüfungsarbeiten beruhten auf der Zusammenstellung der erfassten Angaben mit den im veröffentlichten Katalog von Rudolf Drescher aus dem Jahr 1867 enthaltenen Nachrichten sowie mit dem ab 1877 bearbeiteten Katalogen von J. Zimmermann. Sie ließen in die festgelegte Liste (Kaletynowie, Lodowski 1968) auch weitere, in den Ortschaften Melochwitz und KraschnitzHammer gelegene Fundstellen hineinfügen (Hellmich 1930).

\section{FRÜHES INTERESSE FÜR VORGESCHICHTLICHE FUNDE}

Die ältesten Anzeichen für das Interesse dafür, was wir heute als archäologische Funde bezeichnen, stammen aus dem ausgehenden 14. Jh. und beziehen sich auf die ersten geplanten Ausgrabungen, die Ludwig I., Herzog von Brieg, 1390 auf dem Turmhügel in Ritschen durchgeführt hat. Die Grabungen setzten sich jedoch nicht die Erkennung der uralten Wälle, sondern die Suche nach den körperlichen Überresten der Breslauer Bischöfe zum Ziel, deren Bestattungen hier erhofft worden waren ${ }^{7}$. Die Nachrichten zu weiteren archäologischen Forschun-

6 In Rücksicht auf eine spezifische rechtliche Lage - Machtdualismus - in der Kastellanei Militsch umfassten die Archivforschungen auch die Nachrichten zum Schloss in Militsch (mehr zu diesem Thema Młynarska 1960; Paroń 2008).

Vorstellung der Problematik der ältesten Ausgrabungen in Schlesien: Kramarek 1958, 1969, 15; Kramarkowie 1972, 178-179; Abramowicz 1983, 24-26, hier eingehende gen finden wir im 1544 geschriebenen Brief des Breslauer Bürgers Georg Über an Andreas Aurifaber, Hofarzt und Medizinprofessor an der Universität Königsberg. Darin wurden die in der Gegend von Massel (poln. Masłów) bei Trebnitz aufgefundenen Tongefäße beschrieben (vgl. u.a. Seger 1912, 1-16; Kramarek 1969, 230-233) ${ }^{8}$. Breiter angelegte Ausgrabungen wurden an dieser Fundstelle über ein Jahrhundert später vom dortigen Pastor Leonard David Hermann durchgeführt ${ }^{9}$. Die Tätigkeit

Besprechung. Die Stelle von Untersuchungen Ludwigs I. von Brieg wurde bei den 2004 geführten Ausgrabungen lokalisiert (Moździoch, Przysiężna-Pisarska 2008, 250).

8 Im Kontext der Entdeckungen in Massel ist die Problematik der „Töpfe, die in der Erde entstanden seien“, erwähnenswert (Abramowicz 1983, 15-32).

9 A. Abramowicz fügt die Veröffentlichung der Untersuchungen von L.D. Hermann aus dem Jahr 1711 mit einigen anderen, die die Ergebnisse von Ausgrabungen dar- 
Hermanns fällt in die Zeit, als sich vor allem alte Keramikgefäße oder aus Metallen gefertigte Gegenstände eines großen Interesses erfreuten, die in der Regel mit unterschiedlichen Steinanhäufungen von unnatürlichen Merkmalen - Anordnungen von einfachen Konstruktionen im Typ Steinsetzungen oder Schreine - mit vorkamen. Sie wurden meistens bei Agrararbeiten entdeckt ${ }^{10}$. Jene zufälligen Entdeckungen verwandelten sich mit der Zeit, wie es in Massel (Hermann 1711; Seger 1912) oder in Liegnitz (poln. Legnica; Thebesius 1733; Firszt 1994) geschehen war, in Ausgrabungen von viel breiterem räumlichem Ausmaß. Mitunter machten sie schon den damaligen Liebhabern der Altertümlichkeiten die Gefahr auf großen Flächen zuführender Forschungsarbeiten bewusst. Ein Ausdruck dieser Zweifel und zugleich eine der ältesten methodologischen Erwägungen $\mathrm{zu}$ Ausgrabungen war z. B. der gegen Hermann erhobene Einwand, das Gelände des Gräberfelds durch dessen „Exploration“" zerstört zu haben. Dieser erwiderte auf den
Einwand direkt, die Gräber seien heidnisch und sie verdienen die Erhaltung nicht (vgl. Kramarek 1969, 237-239).

In dem Gebiet, das vom Projekt erfasst ist, können die in der 1720 herausgegebenen Arbeit von Georg Anton Volkmann beschriebenen Funde den so frühen Entdeckungen zugerechnet werden. Teilweise - darunter eine Urne - befanden sie sich in der Bibliothek an der Maria-Magdalenen-Kirche in Breslau. Der Verfasser nennt mehrere Gegenstände aus Militsch, ohne jedoch auf ihren Fundort hinzuweisen. Die Einzelfunden sind mit gestochenen Darstellungen dokumentiert (Volkmann 1720, 322323, Taf. VIII und IX) ${ }^{11}$. Doch verwandelten sich diese Funde in keine ernsthafteren Ausgrabungen. Es scheint, dass der grundsätzliche Faktor, der über die Ergreifung solcher Initiativen entschied, das Vorhandensein von einem Milieu oder Personen war, die den Wert der auf diese Weise gewonnenen Gegenstände wahrzunehmen und einzuschätzen vermögen konnten.

\section{MUSEUMSINVENTARE UND TOPOGRAPHISCHE KATALOGE VON FUNDSTELLEN UND EINZELFUNDEN}

Die Arbeiten, die die älteste Periode in der Geschichte der Altertumskunde gewissermaßen abschließen und deren neues Kapitel eröffnen, sind die Werke von Friedrich Kruse (1819) und Johann Gustav Gottlieb Büsching (1820). Die Abhandlung des ersten von ihnen fasst den damaligen Erkenntnisstand von den bekannten Funden aus den heidnischen Zeiten in Schlesien zusammen und leitet gleichzeitig eine Neuheit in die Veröffentlichung derartiger Angaben ein - die Karte der Ortschaften, wo die altertümlichen Gegenstände gefunden wurden. Darin wurden auch die rechtlichen Regelungen zu archäologischen Untersuchungen aufge-

stellen und in der 2. Hälfte des 17. und zu Beginn des 18 . Jh. entstanden sind, in die Gruppe der für die Geschichte der Altertumskunde wichtigen Bearbeitungen ein und die Untersuchungen selbst zählt zu den zweckmäßigen Maßnahmen, die Nachrichten bringen oder die aufgestellten Fragen beantworten sollten (Abramowicz 1983, 191).

10 Über die aus der Erde geborgenen Funde oder sie begleitenden Steinkonstruktionen schrieben unter anderen N. Henelius, F. Lucae, L.D. Hermann, G.A. Volkmann, G. Thebesius, J.A. Zimmerman im 17., 18. und zu Beginn des 19. Jh. nommen, die im Gesetz für Mecklenburg enthalten waren (Kruse 1819, 168-169; Gummel 1938, 435436).

In derselben Zeit, im zweiten Jahrzehnt des 19. Jh., beginnt mit der Errichtung des Königlichen $\mathrm{Mu}-$ seums für Kunst und Altertümer in Schlesien eine neue Etappe des Denkmalschutzes, darunter auch der archäologischen Funde. Bis zu diesem Zeitpunkt gab es in der Hauptstadt Schlesiens nur Altertümlichkeitskabinette an drei Breslauer Kirchen, die neuzeitlichen Ursprungs waren. Infolge des am 30. Oktober 1810 herausgegebenen Erlasses über die Säkularisierung der Klostergüter im Königreich Preußen, kraft dessen die meisten Klostergüter in das staatliche Eigentum übergingen, wurden die öffentliche Sammlungen der Altertümlichkeiten bedeutend bereichert oder sogar aufs Neue angelegt. Die Ordnungsarbeiten an der dadurch entstandenen

11 Die Nachricht über diese Entdeckung wurde auch in der Chronik der Stadt Militsch veröffentlicht (Kluge 1909, 32-33). 
Sammlung wurden Büsching anvertraut ${ }^{12}$. Das 1815 entstandene Museum führte eine neue Qualität in die Dokumentierung und Sicherung der Spuren der Vergangenheit ein. Drei Jahre nach seiner Eröffnung, 1818, wurden die Altertümlichkeiten zum ersten Mal dem Publikum zugänglich gemacht. Die Sammlung umfasste jedoch die Bestände des Altertümlichkeitskabinetts nicht, somit fehlen hierbei die Angaben zu den Funden von Militsch, die aus der Abhandlung von Volkmann bekannt sind (Bandurska 1998, 29).

Büsching war sich jedoch bewusst, dass die im Grunde genommen - zufällig, infolge der Auflösung der schlesischen Klöster gewonnenen Funde keine ausreichende Grundlage für die systematische Sammlung der Altertümlichkeiten und derer Studien bilden dürfen. 1818 appellierte er in den an die Gesamtheit gerichteten Aufrufen, die in ihrem Besitz befindlichen, geschichtlich wertvollen Gegenstände ans Museum abzugeben oder zu verkaufen (Gediga 1995; Bandurska 1998, 30). Gleichzeitig förderte er planmäßige Ausgrabungen (Seger 1912, 175; Burdukiewicz et al. 2016), wobei er einen großen Wert auf Dokumentation von Fundkontext und Fundzusammenhänge legte. Diese Handlungen unterstützte der auf seine Initiative gegründete Verein für Geschichte und Alterthum Schlesiens und die Nachrichten von Funden wurden in der von ihm gegründeten Zeitschrift Blätter für die gesamte schlesische Altertumskunde veröffentlicht (Demidziuk 2010, 205). Dies trug wesentlich zur Aufwertung der heidnischen Altertümlichkeiten als einer selbstständigen Quelle von der Vorgeschichte bei der Forschung der Vergangenheit Schlesiens bei (Kramarek 1970, 210). Im Fall des ehemaligen Kreises Militsch-Trachenberg bereicherten die von Büsching angesammelten Angaben das Fundstellenverzeichnis um weitere Ortschaften, ebenso um diejenigen, in denen sich die frühmittelalterlichen Burgwälle befinden sollten. Die in den Anfängen des 19. Jh. verwendete Dokumentationsmethode

12 J.G.G. Büsching verfasste drei Kataloge, der damals als heidnische Altertümlichkeiten bezeichneten Funde, die sich in den Sammlungen des an der Universität 1815 gegründeten Königlichen Museums in Breslau befanden. Diese Sammlungen wurden in drei Teilen verzeichnet. Der Katalog A umfasste in Schlesien gefundene Tonware (1501 Stück), B - in Schlesien gefundene Gegenstände aus Metall, Stein, Holz und Hausrat, C - alle obigen Fundtypen (696 Stück), die jedoch aus 54 Ortschaften außerhalb Schlesiens stammten (Bandurska 1998, 34). berücksichtigte jedoch nicht eine genaue Lokalisierung der archäologischen Entdeckungen und Funde, infolgedessen ist es derzeit schwer, einzelne Funde mit gegenwärtig bekannten Fundstellen, darunter Burgwällen, in Verbindung zu bringen ${ }^{13}$.

Der vorzeitige Tod Büschings im Jahre 1829 verursachte einen Stillstand im Bereich der Forschung der schlesischen Altertümlichkeiten. Eine Wiederbelebung des Interesses an der ältesten Vergangenheit der Region erfolgte in der 2. Hälfte des 19. Jh. mit der Gründung des Vereins für Errichtung und Erhaltung eines Museums Schlesischer Altertümer, des späteren Vereins für das Museum Schlesischer Altertümer, im Jahre 1858 in Breslau und ein Jahr später mit der Eröffnung des Museums selbst. Am 26. April 1862, kraft einer Vereinbarung zwischen dem Königlichen Museum für Kunst und Altertümer und dem Verein für das Museum Schlesischer Altertümer, nahm das letztgenannte u.a. die vorgeschichtliche Sammlung des Königlichen Museums auf (Bandurska 1998, 36). Die systematischen Ausgrabungen wurden erneut aufgenommen $^{14}$, die Karteikarten von Büsching wurden in Form eines handschriftlichen Bandes bearbeitet, neue Museumsinventare und topographische Kataloge erstellt sowie mit der Kartierung von archäologischen Funden angefangen. In der Denkmalpflege war damals eine museale Strömung deutlich zu erkennen, deren Hauptziel die Sicherung, Dokumentation sowie eine systematische Analyse des angesammelten Fundmaterials war. Der Weg eines Artefakts von seinem Fundort oder von Händen eines privaten Besitzers zur Museumssammlung war jedoch manchmal lang. Beispielweise gelangten die bei den Grabungen des Burgwalls in Militsch im Jahre 1853 geborgenen Funde erst in den 1870er Jahren, an das Museum Schlesischer Altertümer, also beinahe 20 Jahre nach dem Ende der Ausgrabungen.

13 Z. B. Büsching verzeichnet archäologische Funde aus Radziunz und Schmiegrode im Teil der aus anderen Stoffen gefertigten Gegenstände (entsprechend Katalogpositionen B 217, 777, 778; B 479, B 515), er verbindet sie jedoch mit Burgwällen, die er in diesen Ortschaften überhaupt nicht bemerkt.

14 In Schlesien veröffentlichte Hermann Luchs (1826-1887), Mitbegründer des Vereins für das Museum Schlesischer Altertümer und bis zum Lebensende Kustos des Museums Schlesischer Altertümer, im Jahre 1875 eine Beschreibung der Methoden für Durchführung der Ausgrabungen (Luchs 1875). 
Neben den Museumsinventaren wurden parallel topographische Kataloge der archäologischen Fundstellen und Einzelfunde Schlesiens gefertigt. Ihre Verfasser waren R. Drescher und J. Zimmermann. Drescher bearbeitete den Katalog in den 1860er Jahren aus eigener Initiative. Die Grundlage für die Struktur des Katalogs bildete die Anordnung der Funde aufgrund ihrer Lokalisierung gegenüber den Haupt- und Nebenflüssen der Region ${ }^{15}$. Im an der Bartsch und ihren zwei Nebenflüssen, Honigwasser (Polnisch-Wasser) und Branda, gelegenen Gebiet wurden 35 Ortschaften aufgenommen. Darunter fanden sich auch diejenigen, in denen die Burgwälle gelegen waren, also Militsch (Katalognummer 367), Radziunz (Kat.-Nr. 375) und Schmiegrode (Kat.-Nr. 376; Drescher 1867-1868, 80). Drescher weist jedoch darin lediglich lose Funde und nicht die sog. Objekte mit eigenartiger Form im Gelände nach. Die letzteren bezeichnet er als heidnische Ringwälle, gen. Schwedenschanzen und verweist sie nur in den Dörfern KraschnitzHammer (Kat.-Nr. 364) und Melochwitz (Kat.-Nr. 365; Drescher 1867-1868, 80-81). Der Katalog von Zimmermann entstand infolge der Initiative, die die Deutsche Gesellschaft für Anthropologie, Ethnologie und Urgeschichte ergriff. 1871 schlug die Gesellschaft vor, alle archäologischen Fundplätze im Deutschen Kaiserreich zu kartieren. Für Schlesien übernahm diese Aufgabe J. Zimmermann, damals Mitglied des Vereins des Museums Schlesischer Altertümer. Im Interessenkreis dieses Forschers fanden sich zunächst die Ring- und Spitzwälle, erst mit der Zeit erfasste die Dokumentation alle Arten von Fundstellen. Letztendlich entstand ein handschriftliches Verzeichnis archäologischer Fundstellen in Form eines Provinzkatalogs. Die Grundlage für die Anordnung von Objekten wurde die Landesverwaltungseinheit - der Landkreis ${ }^{16}$. Zwar verzeichnet J. Zimmermann neben Einzelfunden vor allem flache Gräber, jedoch er sondert - so

15 Der Katalog wurde auf der Basis unterschiedlicher Quellen erarbeitet, denen zuzurechnen sind: Volkmann 1720, Kruse 1819, Veröffentlichungen in den Blättern für die gesamte schlesische Altertumskunde, Kataloge A und $B$ von Büsching sowie Katalog des Museums Schlesischer Altertümlichkeiten. Bemerkenswert ist das Fehlen jeglicher Informationen über 1853 durchgeführte Grabungsforschungen auf dem Burgwall in Militsch.

16 Eine Besprechung der Kataloge von J. Zimmermann, die im Archiv des Archäologischen Museums aufbewahrt werden - siehe Demidziuk 2010, 209-210. wie Drescher - im angesprochenen Gebiet heidnische Rundwälle in Melochwitz und die heidnischen Rundwälle oder Schwedenschanzen in KraschnitzHammer aus. In den Ortschaften, in denen die gegenwärtige Forschung Burgwälle verzeichnet, das ist in Schmiegrode (Büsching B 515, Zimmermann - handgeschriebener Katalog, S. 31) und Radziunz, zeichnet er lediglich einzelne Funde auf (Steinäxte; Büsching B 479, Zimmermann, handgeschriebener Katalog, S. 31), die zeitlich mit dem Frühmittelalter nicht verbunden sind. Eine wertvolle Ergänzung der oben erwähnten Bearbeitungen bildet der Beitrag desselben Verfassers aus dem Jahr 1876 unter dem Titel Zur Kenntnis der F undstätten prähistorischer Alterthümer in Schlesien, der ein genaueres Bild der vom Forscher verwendeten Typologie gibt. Diese Gliederung vervollständigen die Zeichenerläuterungen der Karte, indem sie unter Alten Orten die Objekte mit erhaltenen Mauerfragmenten (z. B. in Melochwitz) und ohne sie (in Kraschnitz-Hammer) unterscheiden. In den nächstfolgenden Jahren erarbeitete Zimmermann noch einen Katalog, der das gesamte Gebiet der Provinz Schlesien umfasste ${ }^{17}$ und an die topographischen Karten im Maßstab 1:25000 (Messtischblätter) anknüpfte ${ }^{18}$. Dabei wurde die vorher angenommene Typologie verwendet. Im Gebiet des ehemaligen Kreises Militsch-Trachenberg wurden nur Kraschnitz-Hammer und Melochwitz als Alte 0 rte erneut ausgewiesen.

Es ist bemerkenswert, dass derselbe Aufruf der Gesellschaft für Anthropologie, dessen Folge die Tätigkeit von J. Zimmermann war, einen Philologen, Wilhelm Schwartz, Direktor des FriedrichWilhelm-Gymnasium in Posen, zu archäologischen Untersuchungen in Großpolen veranlasste (Kaczmarek 1997, 87 ff. $)^{19}$. Gegenstand seines Interesses waren Fundstellen aller Art. Grundlage für die

17 Exemplar im Museum der Stadt Breslau, Abteilung Archäologisches Museum, im Archiv der Abteilung für Wissenschaftliche Dokumentation, ohne Inventarnummer.

18 Das angesprochene Gebiet umfasst in verschiedenem Grad 12 Blätter markiert als: U ciechow 2566, P reussental 2565, Militsch 2564, Szkaradowo 2563, Korsenz 2562, Hernstadt 2561, Gr. Bargen 2634, Trachenberg 2635, Friedrichskirch 2636, Katholisch-Hammer 2637, Kraschnitz 2638, Prausnitz 2705.

19 Es ist zu berücksichtigen, dass die Idee der archäologischen Karte ein Verzeichnis von Ortschaften einer angegebenen Region mit der Beschreibung gefundener Denkmäler und einer schematischen Lagebezeichnung der Fundstellen bedeutete, somit ist dies eine Art Kartei und 
Bearbeitung, neben Angaben von den Recherchen in Privatsammlungen und Umfragen, wurden auch die von Schwartz geführten Feldforschungen. Im Bereich seiner Studien fand sich auch teilweise das Gebiet am oberen Bartschlauf, und die direkte Anregung für diese Untersuchungen war die Nachricht über die in dieser Region vorhandenen Pfahlbauten. Schwartz führte seine Forschungen u.a. in Topola und Lekocyn (poln. Łąkociny; Podgrzybów) durch, indem er als erster die Grabungsmethode für derartige Funde im Bereich des großpolnischen Teils des Bartschtals einsetzte (Kaczmarek 1997). Er schlug auch seine eigene Typologie für die Burgwälle vor und setzte diese Objekte ins 10.-11. Jh. (Schwarz 1875-1882). Die Ergebnisse seiner Arbeiten veröffentlichte er in den Jahren 1875-1882 (Kaczmarek 1997, 93). Die Abhandlung von Schwartz war nicht die einzige für das südliche Großpolen. Beinahe gleichzeitig erschien das Buch von Jan Nepomucen Sadowski zum Warthe- und Bartschgebiet (Sadowski 1877), in dem der sich in Großpolen befindliche Ostteil des letztgenannten Flusses aufgenommen worden war. Diese Bearbeitung, die wohl eine Initiative der polnischen Forschungskreise war, stellte eine Zusammenstellung von vorgeschichtlichen Funden und Fundstellen, darunter Burgwällen, dar.

\section{ENTSTEHUNG DES INTERESSESAN BURGWÄLLEN ALS EINER DER SONDERFORMEN DER ARCHÄOLOGISCHEN FUNDSTELLEN}

Da die Interessen der Liebhaber von Altertümern sich vornehmlich auf die in der Erde geborgenen Einzelfunde konzentrierten, beschäftigten sie sich vor allem mit Gräberfeldern, die für sie als eine Art „Fundgrube“ der altertümlichen Gegenstände faszinierend erschienen. Die Attraktivität solcher Fundstellen kam daher, dass man davon die ganzen Gefäße (Urnen) und oft auch relativ gut erhaltene Metallfunde bergen konnte.

Auf eine völlig andere Weise wurden die gegenwärtig als Burgwälle gedeuteten Objekte wahrgenommen, und die - sowohl in den früheren Zeiten als auch heutzutage - in Gestalt von Objekten erhalten geblieben sind, die eine im Gelände gut erkennbare Form aufweisen. Die unter den lokalen Gemeinschaften festgehaltenen Eigennamen derartiger Orte, die vor allem auf den Karten überdauerten, belegen die traditionelle Überzeugung über ihren anthropogenen Ursprung und eine Militär- oder Residenzfunktion. Die neuzeitlichen Geschichtsschreiber und Kartographen scheinen jedoch nicht zu bemerken, dass die mit den Terminen Schwedenschanzen oder Rundwälle bezeichneten Objekte Überreste von Burgen mit vorgeschichtlicher oder frühmittelalterlicher Genese darstellen.

Wie und auf welche Weise ist das Interesse an Burgwällen im Gebiet Schlesiens entstanden und insbesondere an denjenigen, die in seinem nordöstlichen Teil gelegen waren? Sind die die Stadt

keine Landkarte, auf der die Lage der Fundstellen markiert wurde.
Militsch betreffenden Formulierungen, die in den Quellen aus dem 18.Jh. enthalten sind, als Ausdruck von den Erinnerungen an alte Burgen einzuschätzen, so wie im Lexikon von Johann Heinrich Zedler, wo die Stadt als ein Städtlein, mit einem uralten und ehemals sehr fest gewesenen Schlosse bezeichnet wird (Zedlers-Lexikon, Bd. 21, 123), oder in der Beschreibung Schlesiens von Friedrich Albert Zimmermann, in der das Fehlen von der Nachricht zur Entstehungszeit der Stadt betont wird, indem zugleich verwiesen wird, dass das hiesige Schloß ehedem eine ansehnliche Veste gewesen, und solches sehr alt sein muß (Zimmermann 1783-1796, 7, 374)? Die beiden Verfasser beziehen zwar ihre Angaben zweifellos auf das linksufrige Schloss in Militsch, das ab 1590 Sitz der Familie Maltzan war, ihre Äußerungen können allerdings auch die Spur einer älteren Tradition gewesen sein, die die Urzeitigkeit der hiesigen Besiedlung bezeugt.

Auf fehlendes Nachdenken über die überwiegend in Form unterschiedlicher, in sich oft Holzkonstruktionen bergender Erdaufschüttungen erhaltenen Objekte weist die im ersten Viertel des 19. Jh. niedergelegte Ausarbeitung von Johann Gottlob Worbs hin, die - wie der Verfasser selbst betont die Aufmerksamkeit auf die bisher von den Historikern übergangenen schlesischen Burgen (Worbs 1821, 507-510) lenken sollte. Bezeichnendes Beispiel ist hierbei erneut die Residenz in Militsch. Indem Worbs die Bulle von Innozenz IV. aus dem Jahr 1245 heranzieht, nennt er zwar unter den angesprochenen Bauwerken Militsch und Sandewalde (poln. Sądowel) - die Orte, wo sich Burgwälle 
befinden - doch er tut es aufgrund der dort vorhandenen gemauerten Bauten (Militsch) oder derer Überreste (Sądowel). Für Worbs scheint es somit selbstverständlich, dass in Militsch das linksufrige Schloss in der päpstlichen Bulle erwähnt wird und Sandewalde ist für ihn nicht wegen der vorhandenen Wallanlagen, sondern eines (späteren) gemauerten Bauwerks interessant ${ }^{20}$. Diese Überzeugung herrscht wahrscheinlich in einem größeren Teil des 19. Jh. Noch einmal erscheint sie in der um die Mitte dieses Jahrhunderts entstandenen Bearbeitung (Schloß 1841, 177-179), in der die in der päpstlichen Bulle von 1155 genannte Burg mit dem sog. alten Schloß am linken Bartschufer identifiziert wird (Gottschalk 1928a, 9/12). Man darf vermuten, dass zu solcher Wahrnehmung des linksufrigen Schlosses die Errichtung einer neuen, klassizistischen Residenz im ausgehenden 18. Jh. von Maltzans beigetragen hat. Somit wurde das mittelalterliche Bauwerk gleichsam automatisch im lokalen Bewusstsein zum alten Sitz und die Erinnerung an den anthropogenen Ursprung des Hügels am rechten Flussufer wurde getilgt.

Ein tieferes Interesse an den schlesischen Burgwällen bringt erst der Beginn der 2. Hälfte des 19. Jh. Als Wendejahr gilt 1857, als der Beitrag eines Liegnitzer Apothekers F.W. Jaekel, Korrespondenzmitglied der Schlesischen Gesellschaft für Vaterländische Kultur über die sog. Schwedenschanzen in Schlesien erscheint (Jaekel 1857, 56$60)$. Von den Abhandlungen über die Wallanlagen in der Lausitz von Karl Preusker aus dem Jahr 1830 (Preusker 1830) und Carl Friedrich Mosch aus dem Jahr 1855 (Mosch 1855) beeinflusst, fordert er eine im breiteren historischen und kulturellen Zusammenhang geführte Untersuchung der schlesischen Wallanlagen, von ihm Ringwälle oder Erdwälle genannt, zu unternehmen und, darauf folgend, eine wissenschaftliche Bewertung bisheriger Meinungen

\footnotetext{
20 Während der 2004 von D. Nowakowski geführten Grabungsforschungen wurden Kulturschichten auf dem Burgwall in Sandewalde freigelegt, die die spätmittelalterliche Besiedlung bezeugen (Nowakowski 2008). Die auf dieser Fundstelle vorhandenen spätmittelalterlichen Bebauungs- und Wallüberreste wurden auch von invasionslosen Untersuchungen bestätigt (Kiarszys 2015). Eine Analyse der Karte von Ch.F. von Wrede weist auf einen noch um die Mitte des 18. Jh. im Bereich des Burgwalls in Sandewalde bestehenden gemauerten Bau hin. Die in den Jahren 2004-2006 in Militsch geführten Forschungsarbeiten ließen solche Überreste nicht ermitteln.
}

in diesem Bereich. Mit dem Auftritt Jaekels hing wohl die Veröffentlichung des Forschungsberichts über die vier Jahre zuvor durchgeführten Untersuchungen auf dem Hopfenberg in Militsch zusammen, die 1857 in der lokalen Zeitschrift M ilitscher Kreisblatt (M ilitscher 1857) erschien ${ }^{21}$.

Diese Mitteilung ist ein bedeutendes Zeugnis für den damaligen Erkenntnisstand der schlesischen Burgwälle. Es ist sowohl eine Spur für das erwachte Interesse an der ältesten Lokalgeschichte, als auch die einzige Überlieferung über sehr frühe Ausgrabungen und sie belegt gleichzeitig die fehlenden Kompetenzen in den Kreisen, die derartige Aufgaben vorgenommen haben. Aus dem Forschungsbericht ergibt sich, dass am 13. Juli 1853 eine Gesellschaft für die Ausgrabungen gegründet wurde, die, nachdem sie die Erlaubnis vom Geländebesitzer namens Schmidt - erhalten hatte, im August desselben Jahres die Untersuchungen aufnahm. Es lässt sich nicht bestimmen, was der direkte Anlass für die Grabungen auf dem Hopfenberg in Militsch gewesen ist: spielten dabei Erkenntnisfragen eine Rolle oder war es nur das Verlangen nach Fundstücken, die dann in eine Privatsammlung gelangen sollten? Im Bericht wurden stattdessen die in der lokalen Gemeinschaft umlaufenden Volkssagen erwähnt, die unter anderen über einen dort verborgenen wertvollen Schatz sowie von zwei in Militsch bestehenden Schlössern und einem sie verbindenden unterirdischen Gang berichteten (Schloß 1841, 189). Der Verfasser der Notiz war sich, wie es scheint, der Irrationalität der letztgenannten Überlieferung bewusst, da die beiden Anlagen von der Bartsch und Sumpfwiesen getrennt waren. Der Bericht enthielt Nachrichten zur Lage des Burgwalls (1000 Schritte nördlich der Stadtbebauung) sowie dessen damaliger Bestimmung (Ackerfeld). Es wurde auch auf das Vorhandensein eines anderen, kleineren Hügels hingewiesen, der nordwestlich des Hopfenbergs lag und der Kleine Hopfenberg genannt wurde, aktuell Fundstellen 9 und 10 in Militsch - Gräberfeld und die Vorburgsiedlung. Die Form des höheren Hügels wurde als Ringwall bezeichnet und Beleg für seinen

21 Der Bericht ist für den 29. März desselben Jahres datiert. Seine Kopie in Form einer zu Beginn des 20. Jh. gefertigten Maschinenschrift wird zurzeit im Staatlichen Archiv in Breslau mit zwei Aufnahmen der Keramik und Einzelfunden aufbewahrt. Die damals gefundenen Artefakte befinden sich im Archäologischen Museum in Breslau (zurzeit Abteilung des Museums der Stadt Breslau). 
anthropogenen Ursprung sollte eine umlaufende Vertiefung gewesen sein, woher, nach Ansicht des Verfassers, der Stoff für den Bau des Walls gewonnen wurde ${ }^{22}$. Die Form des Walls selbst wurde als Ellipse bezeichnet, mit längerem Durchmesser von 180 und kürzerem von 150 Schritten. Die Wallhöhe maß zwischen 20 und $28 \mathrm{Fu}$. Den Wall umgab eine kesselförmige Vertiefung ${ }^{23}$. Im Bericht fehlen genaue Informationen zur Lage der Ausgrabung. Wir erfahren lediglich, dass ein Areal mit einer Fläche von 12-16 Quadratfuß abgesteckt worden ist und die Tiefe der Ausschachtung betrug 20-26 Fuß24. Im Schnitt wurde eine Konstruktion aus Steinen und gebranntem Backstein freigelegt ${ }^{25}$. Es wurden auch Fragmente von verkohlten Balken aufgedeckt, die man heute als Bestandteile von Holzkonstruktionen deuten darf ${ }^{26}$. Der Berichterstatter, war nicht sicher, ob die Stein- und Backsteinkonstruktion getrennt standen oder irgendwie miteinander verbunden waren, da keine Spuren von Bindestoff vorhanden waren. Bei den Grabungen konnten zahlreiche Gegenstände geborgen werden, allerdings, wie im Bericht festgestellt wurde, machte das Fehlen von Vorgeschichtlern unter den Grabungsteilnehmern eine Datierung des Walls unmöglich. Die auf dem Hopfenberg geborgenen Artefakte gehörten zu den Gegenständen des alltäglichen Gebrauchs (Messer, Schlüssel archaischer Form, Spinnwirtel, Tongefäße, darunter eine gut erhaltene Vase), aber auch zu den Luxuswaren (Sporen aus Eisen und Kupfer, Edelsteinperlen, darunter eine unheimlich verzierte Scheibe aus Hirschgeweih ${ }^{27}$ ). Aus dem Bericht ergibt sich, dass mehrere Geweihstücke

22 Wahrscheinlich handelt es sich um ein Fragment des Burggrabens, der die Burg von der Vorburgsiedlung - dem Kleinen Hopfenberg - getrennt hat.

23 Heutzutage ist seine Form nur mit Mühe ablesbar, denn die Wälle wurden in hohem Maß umgepflügt.

24 In Rücksicht auf die heutigen Ausmaße der Fundstelle kann man die Grabung im nördlichen Teil des Burgwalls lokalisieren, dort ist der Wall heutzutage am höchsten. Die Informationen über eine vorhandene innere Vertiefung lassen vermuten, dass die übrigen Wallteile auch höher gewesen sein konnten.

25 Vielleicht geht es um Lehmbewurffragmente.

26 Die 2004 auf dem Militscher Burgwall geführten Ausgrabungen bestätigten einen teilweise verbrannten Wall (Kolenda 2008)

27 Es handelt sich wohl um eine Scheibe oder einen Belag, zurzeit verschollen und nur aus älterer Literatur bekannt. sowie zwei Eberzähne und zwei große Zähne mit einer Bissfläche von einem schlesischen Quadratzoll angetroffen wurden. Als Überrest von Rohstoff oder Herstellungsabfall kann wahrscheinlich dies gedeutet werden, was der Beschreibung nach einem Stück Steinkohle ähnelte ${ }^{28}$ sowie Fragmente von Blei- oder Silbererz. Die Aufmerksamkeit der Sucher fesselten Jagdgeräte, Pfeilspitzen und mehrere andere Kleingegenstände. Bemerkenswert ist die Nachricht über die Auffindung der Bruchstücke eines Kachelofens, was Eck- und Simskacheln von sehr archaischer Form und mit ungewöhnlichen figuralen Darstellungen hätten belegen können. Die Untersuchungen umfassten auch den benachbarten Hügel, der Kleine Hopfenberg, wo früher bei den Ackerarbeiten menschliche Skelette gefunden wurden.

Der oben angeführte Bericht veranschaulicht einen geringen Wissensstand, unprofessionellen Charakter der Ausgrabungen sowie Vertrauen der Sucher auf lokale Traditionen und sagenhafte Überlieferungen. Ein großer Mangel des Berichts ist Fehlen von der Zeichendokumentation sowohl des Burgwalls selbst, der damals viel weniger zerstört war als heute, als auch einer Skizze oder eines Plans, der auf die Lage der Grabung hinweisen würde.

Die bei den Ausgrabungen geborgenen Funde wurden weder an das Museum in Breslau überwiesen, noch wurde deren Bestandsaufnahme durchgeführt und letztendlich wurden sie verstreut. Auffällig ist auch die Tatsache, dass die Veröffentlichung des Berichts keine Fortsetzung der Untersuchungen brachte und dies obwohl sie mit einer kurzen Notiz vom Auftritt Professors Heinrich Robert Göppert eingeleitet wurde, in dem er bereits den veröffentlichten Beitrag zu frühmittelalterlichen Burgwällen von Jaekel anführte. Jaekel selbst verwies als Ziel seiner Forschungen die Anregung einer Diskussion über die in Schlesien erkannten, in Europa zahlreich vorkommenden und zur wissenschaftlichen Debatte stehenden Erdwallanlagen (Jaekel 1857, 58). Er berief sich insbesondere auf die Ausarbeitungen zu Lausitzer Burgwällen, die den Interessengegenstand der Forschung und der wissenschaftlichen Erwägung beinahe $\mathrm{ab}$ dem Beginn des 19. Jh. bildeten (Rösch 1805; Cotta 1839; Schiffner 1840).

28 Wahrscheinlich handelt es sich hierbei um Felsstoff oder ein Fragment eines Steinartefakts. 
Das damals eingeleitete Interesse für die schlesischen Wallanlagen brachte weitere Bearbeitungen, sowohl in Form von Beiträgen (Jaekel 1865; Zimmermann 1876; Söhnel 1896) als auch Katalogen (Drescher 1867-1868). Die schlesischen Wallanlagen kamen in Sammelbearbeitungen vor, die die Provinz selbst (Vug 1890; Söhnel 1896), als auch größere Reichsgebiete (Schuster 1869; Behla 1888) umfassten. Deren Verzeichnis erweiterte sich allmählich; um die Mitte des 19. Jh. konnte auf etwa 40 Wälle verwiesen werden, während Drescher in seinem Katalog aus den 1860er Jahren bereits 78 in Schlesien aufzählen konnte. J. Zimmermann gab für die Oberlausitz und Schlesien insgesamt 116 Ringwälle an (Zimmermann, handgeschriebener Katalog; Zimmermann 1876, 90) und Hermann Söhnel im Jahre 1896 - etwa 28029 (Söhnel 1896, 91). 1888 stellte Robert Behla in seiner Ausarbeitung u.d.T. Die vorgeschichtlichen Rundwälle in Deutschland: eine vergleichend-archäologische Studie, die den Wissenstand zu Burgwällen im Gebiet Ostdeutschlands zusammenfasste, fest, dass die Provinz Schlesien das an Ringwällen reichste Gebiet Deutschlands ist (Behla 1888, 161) ${ }^{30}$.

Interessengegenstand der Forscher von alten Wällen in der 2. Hälfte des 19. Jh. war vor allem ihre ursprüngliche Funktion sowie Datierung und was daraus folgt - gemäß den damals geltenden Tendenzen und Methoden in der Geschichtsforschung (Gramsch 2006) - Anknüpfung derer Entstehung an eine bestimmte ethnische Gruppe. Die Datierungsversuche wurden aufgrund einer Analyse der auf diesen Fundstellen geborgenen Einzelfunde unternommen. Unter möglichen Funktionen der Wälle wurden genannt: Versammlungs-, Opferund Bestattungsplatz, es wurden aber auch potentielle Wehr- und Wachfunktionen angedeutet (Peuskert 1830, passim; nach ihm Söhnel 1896, 103). In der Frage der Identifizierung der Wallerbauer gingen die Meinungen der Forscher auseinander, z. B. während Drescher darin das Werk von den Slawen sah (Drescher 1867-1868, 93), beschreibt und analysiert Oskar Schuster sie als germanische Bauwerke (Schuster 1869, 33-59). Diese Forschungsfrage teilte die Forscher der Geschichte Schlesiens meh-

29 Man kann nicht ausschließen, dass diese Zahl auch spätere gemauerte Bauten enthält.

30 Ein steigendes Interesse an vorgeschichtlichen Wällen bezeugt auch die Veröffentlichung von Rudolf Virchow $(1872,568)$. rere Jahrzehnte lang. In dieser Zeit tauchten auch zum ersten Mal denkmalpflegerische Gedanken auf. Behla hebt hervor, dass die Holz-Erde-Konstruktionen nach wie vor dem Ausbau der Verkehrsinfrastruktur und der immer stärkeren Landwirtschaft zum Opfer fallen und fordert eine dringende Aufnahme und das Dokumentieren von allem, was zur Festhaltung und Erweiterung des Wissens darüber beitragen könnte (Behla 1888, 7). Eine $\mathrm{Zu}$ sammenfassung der Forschungsleistungen des 19. Jh. im Bereich der Burgforschung in Schlesien enthält die Bearbeitung von Hermann Söhnel u.d.T. Die Burgwälle Schlesiens nach dem gegenwärtigen Stand der Forschung (Söhnel 1896), der sowohl die zugängliche Literatur als auch die im Museum Schlesischer Altertümlichkeiten aufbewahrten Akten (die sog. Burgwallakten) ausgewertet hat, aber auch im bestimmten Bereich eigene Beobachtungen führte. Von populärwissenschaftlichem Charakter war hingegen das Buch von Oskar Mertins u.d.T. Wegweiser durch die U rgeschichte Schlesiens, der sich entscheidet die Wallanlagen eindeutig mit dem Begriff Burgwall zu verbinden und deren Bau den Slawen zuschreibt (Mertins 1906, 129-135).

Nach der Mitte des 19. Jh. waren die Untersuchungen der in Schlesien gelegenen Wallanlagen verhältnismäßig intensiv und weitläufig, deshalb überrascht ein wenig die Tatsache, dass bis zum Ende dieses Jahrhunderts im Projektgebiet, d.i. im nordöstlichen Teil Schlesiens, nur drei Fundstellen - Burgwall in der Ortschaft Guhre, zwischen den Dörfern Guhre und Strebitzke (poln. Trzebicko) gelegen, sowie die Objekte in den Dörfern Melochwitz und Kraschnitz-Hammer, die gegenwärtig nicht erkennbar und als Burgwälle nicht klassifiziert sind - nachgewiesen wurden. Eben diese Fundstellen meinte auch Söhnel, indem er über zwei Wallanlagen im ehemaligen Kreis Militsch schreibt (Söhnel 1896, 91). Die Burgwälle aus dem Gebiet des Bartschtals sind auch in Dreschers Katalog spärlich vertreten, was vielleicht mit dem vorzeitigen Tod des Forschers zusammenhängt, der seine Arbeit nicht zu Ende führen konnte. Zugleich scheint sicher zu sein, dass er den Bericht über die 1853 in Militsch geführten Untersuchungen nicht kannte.

Besonders auffällig ist, dass die Forscher im 19. Jh. den Burgwall auf dem Hopfenberg in Militsch übergehen. Er wurde auch von Zimmermann in seinen Katalogen im Teil über altertümliche Orte (Alte Orte) außer Acht gelassen. Wenn man den Sachverhalt aus der Sicht von vor über 150 Jahren 
betrachtet, kann man vermuten, dass dieser von einem Zusammentreffen ungünstiger Umstände verursacht wurde. Der Burgwall in Militsch wurde als erster in dieser Region erforscht und wohl aus diesem Grund konnten keine richtigen Methoden bei seiner Untersuchung eingesetzt werden. Es fehlten vor allem schriftliche und zeichnerische Dokumentationen. Ein kurzer Bericht über die unternommenen Grabungen erschien erst vier Jahre nach der Abschließung der Grabungen und ausschließlich in der lokalen Zeitschrift (M ilitscher 1857). Dem Bericht nach wurde die Rezeption der Forschungsergebnisse wegen des Fehlens der Altertumsforscher unter den Grabungsteilnehmern sowie dem oben genannten Missverständnis in Bezug auf die Bestimmung der Lage des frühmittelalterlichen, in den Schriftquellen erwähnten Burgwalls, negativ beeinflusst. Überdies erregten die Untersuchungen keine Aufmerksamkeit in Breslau, wo zwar das Königliche Museum für Kunst und Altertümer tätig war, allerdings war es damals so profiliert, dass es in erster Linie die Denkmäler der antiken Welt ansammelte. Letztendlich wurden die Funde erst in den 70er Jahren des 19. Jh. ans Königliche Museum für Kunst und Altertümer überwiesen, wahrscheinlich ohne ausreichende Nachrichten über die Umstände deren Gewinnung. Dass die Erkennung der Militscher Burg anderweitig hätte verlaufen können, belegt das Beispiel des Burgwalls im obenerwähnten Topola. Die dort in den Jahren 1872-1874 von Wilhelm Schwartz durchgeführte planmäßige Erkundung brachte eine richtige Bestimmung der Funktion und Datierung des Walls sowie Veröffentlichung und Popularisierung der Forschungsergebnisse (Schwartz 1875-1882, passim).

\section{BURGWÄLLE IN DER KARTOGRAPHISCHEN DOKUMENTATION}

Den Kontext für eine Analyse von kartographischen Quellen bildet die einzigartige Physiographie des Bartschtals, denn sie bedingte in bedeutendem Maß den Prozess der Identifizierung und Dokumentation der in seinem Gebiet lokalisierten Wallanlagen. Ein gemeinsamer Zug aller im Projekt analysierten Burgwälle ist ihre Lage in den Flusstälern (der Bartsch und derer Nebenflüsse), die oft ihren Verlauf änderten. Zugleich begünstigten die spezifischen natürlichen Gegebenheiten dieses Teils Schlesiens das Anlegen von ausgedehnten Fischteichen. Dies lässt vermuten, dass die lokale Gemeinschaft die Topographie der Flusstäler gut kannte. Mittelbar wird dies durch die bis heute erhaltene Kulturlandschaft in der Gegend der Ortschaften Guhre und in Breslawitz belegt. Der erste der Burgwälle, zurzeit im Dorf gelegen, befindet sich in einem kleinen, fluvioglazialen Tal eines namenlosen Wasserlaufs, der in der frühen Neuzeit zum Bau von Teichen benutzt wurde. Die Teiche wurden in der direkten Nachbarschaft der Wallanlagen angelegt und einer der Dämme wurde dergestalt aufgeschüttet, dass er sich mit den Burgbefestigungen von der südlichen Seite verbindet. Eine ähnliche Lage ist in der Nähe des Burgwalls in Breslawitz zu finden, von dessen Wällen die Dämme der nahe gelegenen Teiche $\mathrm{zu}$ sehen sind. Auf den nacheinander gefertigten Karten, angefangen mit der Ausarbeitung von Johann Wolfgang Wieland bis hin zu den Karten des
D eutschen Reichs (die sog. M esstischblätter), kann man die Differenzierung von Lage, Anzahl, Ausmaßen und Form der in der Nähe dieser Fundplätze angelegten Teiche erkennen. Dies belegt, dass die lokale Gemeinschaft das Gelände durchdrungen, darunter auch die gegenwärtig als Burgwälle erkannten Objekte. Es bedeutet aber nicht, dass jene Gemeinschaft sie richtig als Überreste frühmittelalterlicher Burgwälle zu identifizieren vermochte.

Auf den Landkarten aus dem 17. Jh., also denjenigen, die in der Zeit gefertigt worden sind, die in der Kartographiegeschichte die Vor-Landesaufnahme-Periode genannt wird, fehlen frühmittelalterliche Burgwälle prinzipiell. Auf diese Karten wurden die Bartsch und einzelne Ortschaften in ihrem Tal, so wie Militsch, Trachenberg, Sulau (poln. Sułów) oder Neuschloß (poln. Nowy Zamek) eingetragen. Die Quellengrundlagen dafür bildeten die Angaben, die vornehmlich von den geographischen Beschreibungen und bereits bestehenden Atlanten gewonnen wurden, die Geländekenntnis aus eigener Anschauung war hingegen beträchtlich beschränkt ${ }^{31}$.

31 Glaubwürdigkeit, Genauigkeit und Detailliertheit der ältesten Abbilder des Geländes waren Ergebnis von einigen Faktoren, so wie: die Anzahl der angesammelten Quellenangaben, technische Fertigkeiten in Ausführung der Landesvermessung, Wissen und Erfahrung des Verfassers über das kartographierte Gebiet oder Kartenausrich- 
Die einzige Landkarte, die der Periode vor der Landesaufnahme zugerechnet werden kann und auf der ein Burgwall im Kreis Militsch-Trachenberg festgehalten worden ist, ist die Karte der Herrschaft Trachenberg von Johann Christian Berger aus dem Jahr $1676^{32}$ (Kowalski, Kozica 2010, Karte 10, 3435). Darauf wurde ein in dessen Raum angelegter Garten in der Ortschaft Kendzie markiert ${ }^{33}$ (Abb. 2:1). Aus dessen Darstellungsweise ergibt sich, dass das Gelände in der Vergangenheit ziemlich stark umgestaltet worden ist. Die ursprüngliche Funktion dieses Fundplatzes wurde verwischt und aus der Erinnerung der lokalen Gemeinschaft getilgt. Es wurde ein neuer Bestandteil der Kulturlandschaft geschaffen, welcher der damaligen Realität und den Bedürfnissen entsprach. Diese Umgestaltungen hatten ihren Anfang spätestens in der ersten Hälfte des 17. Jh, als die Schweden während des Dreißigjährigen Krieges an dieser Stelle eine Kanonenschanze angelegt haben (Hoffmann 1927, 10/11). Bedeutendere Änderungen in der Wallanlage traten jedoch in der Folge der Errichtung einer ausgedehnten barocken Gartenanlage ein ${ }^{34}$, die danach auf den

tung. Die Genauigkeit und Detailliertheit dieser Abbilder wurden auch vom Kartenmaßstab sowie der Größe des kartierten Geländes beeinflusst. Beispielweise zeigt die Karte Schlesiens von Martin Helwig aus dem Jahr 1561 die Bartsch, Żmigród, Sulau und Militsch (Kowalski, Kozica 2010, Karte 1). Auf der Karte von Jonas Scultetus aus dem Jahr 1638, die den Titel Herzogtum Schlesien trug, wurden die Bartsch und Orla sowie Militsch, Sulau,Trachenberg und Korsenz markiert (Lindner 1987, Kar.-Nr. 12).

32 J.C. Berger, Delineation Liberare in Silesia Dynastiae Drachenberg Illustrissimo Domino Francisco L. B. de Nesselrode et Drachenberg, Dynastie in Herten, Stein, Ehrenstein, et Prausnitz, S.ae. Caes.ae. M aj.tis Camerario, ducatus M ontium Camerario et Mareschallo haereditario Sereniß. Coloniensis Consilario intimo et Locum: tenenti Vesti Domino Suo gratioso, .... um 1680.

33 Eine Neuauflage der Karte erschien im Jahre 1681 (Kowalski, Kozica 2010, 37) und 1720 wurde eine Kopie von Petrus Schenk II herausgegeben (Kowalski, Kozica 2010, Karte 11, 39-41). Eine schwarz-weiße Fassung dieser Karte wurde 1987 veröffentlicht (Lindner 1987, Kar.Nr. 83). Sie wurde für einen besonderen Auftrag gefertigt und stellte den Rechts- und Vermögensstand der Erben von M. von Hatzfeldt fest (Czechowicz 2008, 93; Kowalski, Kozica 2010, 36-37).

34 Wahrscheinlich fand es statt, nachdem die Herrschaft von Trachenberg von der Familie von Hatzfeldt übernommen worden war, also nach 1641. Der Garten besteht aus einem kreisförmigen nordwestlichen Teil, wo
Karten als ein Lust-G arten ${ }^{35}$ bezeichnet wurde. Die späteren Karten dokumentieren auch eine Bebauung auf dem Burgwallinneren sowie der Wallkrone, die dann die Stratigraphie des Walls beträchtlich störte. Es ist bekannt, dass noch um die Mitte des 19. Jh. ein fürstlicher M eierhof im Bereich des Walls bestand (Knie 1845, 282). Auf der Landkarte von Berger wird der Garten mit den Bartscharmen umgeben, somit macht die ganze Anlage den Eindruck einer Insel. Im Kontext der Beziehung zwischen der Lage der wehrhaften Fundplätze und der Hydrologie stellt sich die Frage, ob die Burg in Kendzie ursprünglich von Wasser und Sumpfgebieten umgeben war oder die auf den Landkarten des 17. und 18. Jh. sichtbare hydrologische Lage der Bartsch das Ergebnis der später Umgestaltungen von anthropogenem oder natürlichem Charakter war.

Im 18. Jh. wurden die schlesischen Lande, die bis zur Mitte dieses Jahrhunderts ein Teil der habsburgischen Monarchie und später des preußischen Staates waren, mit einigen neuen topographischen Landesaufnahmen erfasst. Sie dienten den Militärzwecken, aus diesem Grund wurde für die Karten der Maßstab eingesetzt, der die Kartierung einzelner Elemente des Geländereliefs ermöglichte, darunter Erhebungen von so geringen Ausmaßen wie die Burgwälle. Dadurch sind auch diese Landkarten vom gegenwärtigen archäologischen Gesichtspunkt von großem Erkenntniswert.

Die in diesem Bestand durchgeführte Archivforschung wies nach, dass die Burgwälle gegen Ende der ersten Hälfte des 18. Jh. auf den Karten Schlesiens erschienen, also in der Zeit, als man mit den kartographischen Bearbeitungen aufgrund der Landesvermessungen begann. Die erste Landkarte, in der sie markiert wurden, stammt von Johann Wolfgang Wieland und Matthäus von Schubarth, ist ins Jahr 1739 datiert und im von den Hommanischen

die ursprüngliche Form des Burgwalls erhalten wurde und einem spindelförmigen südöstlichen Teil. Eine Analyse des Gartenplans weist eine zentrale Allee auf, die durch seine ganze Länge hin führt, auch den Teil, wo ursprünglich der Burgwall gelegen hatte. Überdies wurde das Innere mit kleineren quer zur Hauptallee gelegenen Pfaden geteilt. In der Anlage waren die Wälle wahrscheinlich ein Bestandteil der Komposition, was die Anordnung der Pflanzen, durch deren bis heute erhalten gebliebenes Fragment bezeugen kann. Die gesamte Anlage war mit Bäumen und Sträuchern rundherum bepflanzt (Czechowicz 2008, Abb. 62).

35 Im gesamten Text wurde die auf den Karten angenommene Schreibweise der Eigennamen erhalten. 

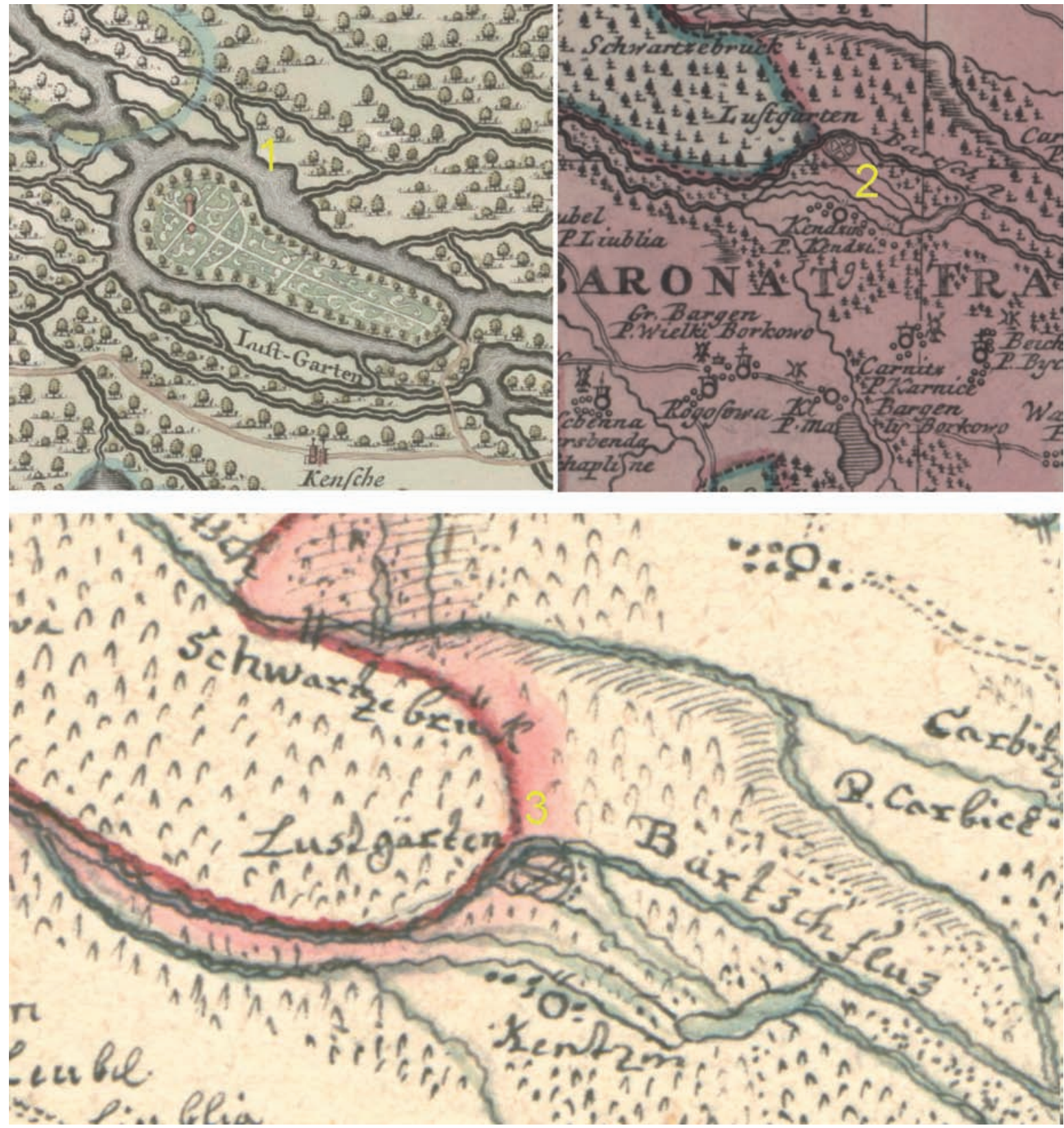

Abb. 2. Burgwall Kendzie - Lustgarten: 1 - Fragment der Karte von J.C. Berger Delineation Liberae in Silesia Dynastiae D rachenberg: Illustrissimo Domino F rancisco L. B. de Nesselrode et Drachenberg, Dynastie in Herten, Stein Ehrenstein, et Prausnitz, Saec. Caesae. Majtis. Camerario, ducatus M ontium Camerario et M areschallo haereditario Sereniß. Coloniensis Consiliario intimo et Locumtenenti Vesti D omino Suo gratioso, .... um 1680, 2 - Fragment der Karte von J.W. Wieland und M. Schubarth Principatus Silesiae O elsnensis. (SBB Preußischer Kulturbesitz, Staatsbibliothek zu Berlin, Sign. Kart. N 14940), 3 - Fragment der Karte von F.B. Werner Special M appa Dynastie Trachenberg Et Status M inoris Sulau vel Zulauf, in: Friedrich Bernhard Werner, Topographia oder Prodromus

Delineati Principatus Lignicensis Bregensis, et Wolaviensis..., Bibliothek der Universität Wrocław, Abteilung der Manuskripte, Sign. Akc. 1948/1094 (elektronisches Dokument: www.bibliotekacyfrowa.pl:14652; Zugang: 20.05.2017) Fig. 2. The stronghold of Kędzie - Lustgarten: 1 - a fragment of the map by J.C. Berger Delineation Liberae in Silesia

Dynastiae Drachenberg : Illustrissimo Domino Domino Francisco L. B. de Nessel rode et Drachenberg, Dynastie in Herten, Stein E hrenstein, et Prausnitz, Saec. Caesae. Majtis. Camerario, ducatus M ontium Camerario et M areschallo haereditario Sereniß. Coloniensis Consiliario intimo et Locumtenenti Vesti Domino Suo gratioso, around 1680; 2 - a fragment of the map by J.W. Wieland and M. Schubarth Principatus Silesiae 0 elsnensis. (SBB Preußischer Kulturbesitz, Staatsbibliothek zu Berlin, cat. no. Kart. N 14940), 3 - a fragment of the map by F.B. Werner Special M appa Dynastie Trachenberg Et Atatus M inoris Sulau vel Zulauf, from: Friedrich Bernhard Werner, Topographia oder Prodromus D elineati Principatus Lignicensis Bregensis, et Wolaviensis..., Wrocław University Library, Department of

Manuscripts, cat. no. Akc. 1948/1094 (digital document: www.bibliotekacyfrowa.pl:14652; accessed: 20.05.2017) 


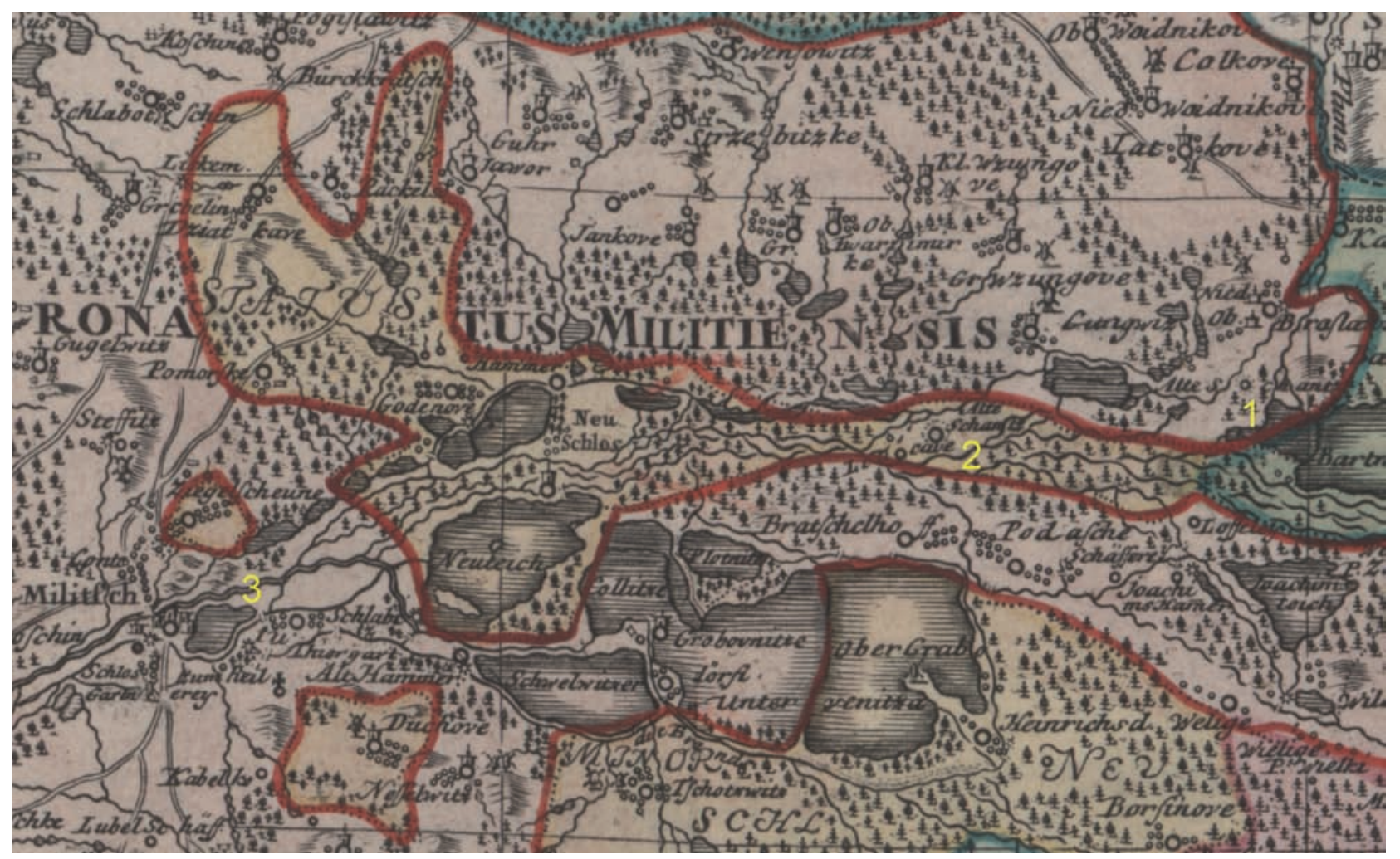

Abb. 3. Markierung der Burgwälle auf der Karte Principatus Silesiae O elsnensis von J.W. Wieland und M. Schubarth (SBB Preußischer Kulturbesitz, Staatsbibliothek zu Berlin, Sign. Kart. N 14940):

1- Breslawitz, 2 - Lelikowe, 3 - Militsch

Fig. 3. Strongholds marked on the map Principatus Silesiae 0 elsnensis by J. W. Wieland and M. Schubarth (SBB Preußischer Kulturbesitz, Staatsbibliothek zu Berlin, cat. no. Kart. N 14940): 1- Wrocławice, 2 - Lelików, 3 - Milicz

Erben in Nürnberg herausgegebenen Atlas Silesiae enthalten ${ }^{36}$. Die Topographie des Kreises MilitschTrachenberg wurde auf der Karte mit dem Titel Prinicipatus Silesiae 0 elsnensis festgehalten. Unter den zurzeit der Forschung bekannten Fundstellen wurden zwei davon angebracht - in Breslawitz und in Lelikowe (Abb. 3). Sie wurden mit einem Zeichen markiert, d.i. es wurde ihre Topographie nicht wiedergegeben, bei jedem ist die Unterschrift Alte Schantz zu sehen. Die beiden Burgwälle sind

36 Johann Wolfgang Wieland, Principatus Silesiae Oelsnensis in suos districtus 0 els Bernstadt und Trebnitz divisi exactissima tabula geographica exhibens insimul circumjatentes dynastias liberas Trachenberg et Militsch cum statibus minoribus F reyhain, Nevschlos, Goschütz et Zulauf ...., veröffentlicht in: Atlas Silesiae Id Est Ducatus Silesiae Generaliter Quatuor Mappis Nec Non Specialiter XVI Mappis Tot Principa Tus Repraesentantibus Geographice Exibitus Addita, Praefatione Qua De Historia Huius Atlantis Agitur Auctoritate Publica In Lucem Emissus Ab Hommanianis Heredibus. Haeretibus Homannianis, Nuernberg 1750. im sumpfigen und bewaldeten, von den Siedlungen entfernten Gelände gelegen. Umso mehr ist auffällig, dass der viel größere und in der Nähe der Stadt gelegene Burgwall in Militsch nicht aufgezeichnet wurde, stattdessen wurde das Gelände, in dem er liegt, auf der Karte durch zwei Wasserläufe in drei kleinere Teile gegliedert, zwischen denen zwei Reihen von jeweils drei Erhebungen eingezeichnet sind. Solche Darstellung dieses Geländes, ohne die größte Erhebung der Burg zu unterscheiden, lässt keine direkte Erkennung dessen Funktion sowie Eigenart und Topographie vermuten. Eine ähnliche Situation entstand beim Burgwall in Guhre, der damals als solcher, trotz einer sorgfältigen Dokumentation der benachbarten Fischteiche, nicht erkannt wurde. Die Anbringung auf den Karten von zwei Burgwällen, in Breslawitz und Lelikowe, könnte davon zeugen, dass diese Geländeformen zu dieser Zeit mit den frühneuzeitlichen Militärobjekten verbunden worden waren. Es ist nur schwierig mit Sicherheit festzustellen, ob hierbei entweder eine ältere Tradition oder die Interpretation der Offiziers-Kartographen, 
die sich aus deren Wissen und Erfahrung ergibt, zum Ausdruck kommt. Auf der Karte wurde auch der Lustgarten in der Ortschaft Kendzie markiert, indem jedoch der Umriss zu einem, das Areal des Burgwalls entsprechenden Kreis mit geometrischer Gliederung umgeformt wurde (Abb. 2:2). Aus der fast 200 Jahren nach der Entstehung der Landkarte verfassten Nachricht wissen wir, dass der Lustgarten im Jahre 1720 seine Funktion verloren hatte und $\mathrm{zu}$ einem typischen Ackerland wurde (Hoffmann 1927, 10/11). Im dritten Viertel des 18. Jh. fertigte Friedrich Bernhard Wernher die Beschreibung des Fürstentums Trachenberg (Abb. 2:3), indem er auf der beigelegten Landkarte noch den Lustgarten markierte, den er als ovales, mit einem Wall umgebenes, am Ufer der Bartsch gelegenes und von zwei in den Fluss mündenden Bächen erfasstes Gelände, das durch zwei Wege kreuzartig geschnitten war, aufzeichnete (Wernher 3. Viertel des 18. Jh., 622).

Beinahe 10 Jahre nach der Abschließung der oben genannten Vermessungsarbeiten wurde eine weitere Landesaufnahme, diesmal im Auftrag der preußischen Regierung, eingeleitet. Sie wurde Christian Friedrich von Wrede anvertraut. Es entstand damals die Krieges Karte von Schlesien, auf der einige Wehrobjekte markiert wurden. Der Kreis Militsch-Trachenberg wurde um 1753 auf den Karten Nr. 15, 16, 17, 21, 22, 23 bearbeitet. Es lässt sich dabei ein sichtbarer Unterschied in der Zahl der Schanzen beobachten, die in dem östlichen Teil des ehemaligen Kreises Militsch-Trachenberg, der einen beträchtlichen Teil des Militscher Becken umfasste, und denen, die in dem westlichen, im Trachenberger Becken gelegenen Teil markiert wurden. Im östlichen Teil wurden die bereits von der Karte von Wieland bekannten Burgwälle in Breslawitz und Lelikowe markiert (Abb. 4:1-2), womit man ihre bisherige Namen übernimmt ${ }^{37}$ (Band V, Karte 15) wie auch die Fundstelle in Guhre, in der unmittelbaren Nachbarschaft der Teiche, die als Redoute bezeichnet wird (Abb. 4:4). Das rechtsufrige Gebiet von Militsch wurde jedoch anders als auf der früheren Karte von Wieland dargestellt. Das ganze Gelände zwischen dem rechten Bartschufer bis an das heutige Dorf Ziegelscheune (poln.Wszewilki) wurde als Sumpfwiesen markiert. Unter den Wie-

37 Vielleicht geschah das unter Einwirkung von Martin Schubarth, Mitverfasser der Karte von J.W. Wieland, der in die Gruppe von Ch.F. von Wrede aufgenommen wurde. sen wurde eine Erhebung punktgenau aufgetragen, die wir heute eben mit dem Militscher Burgwall identifizieren können (Abb. 4:3), als der Hoppe. Berg beschrieben, wobei dieser Name, der sich bis ins 20. Jh. erhielt und von der polnischen Toponomastik als Góra Chmielowa (heutzutage Chmielnik) übernommen, eher einen agrarischen Zweck vermuten $l_{\text {ässt }}{ }^{38}$.Wahrscheinlich wurde auch der Burgwall in Kasawe, in Form einer kleinen, unter einem Labirynth von namenlosen Bartscharmen gelegenen Erhebung markiert. Die drei genannten Fundstellen (Guhre, Militsch, Kasawe) wurden auf die Karte 16 (Band V) aufgetragen. Viel schlimmer sieht die Lage im westlichen Teil des Kreises aus, wo lediglich der Burgwall in der Ortschaft Kendzie festgehalten wurde, dank dessen, dass hier der ehemalige Lustgarten verzeichnet und beschrieben worden war. Es wurden jedoch nicht die Burgwälle in den Ortschaften Schmiegrode und Klein Ossig (Band V, Karte 17), Klein Peterwitz (Band V, Karte 22), Melochwitz und Kraschnitz-Hammer (Band V, Karte 22) markiert.

Auf den Karten von Wrede wurden unterschiedliche Arten der graphischen Markierung alter Wälle eingesetzt. Die in Breslawitz, Lelikowe, Kasawe und Leubel (poln. Lubiel) gelegenen Burgwälle wurden mithilfe einer zentrischen Schraffur dargestellt, die deren charakteristische Form des Rundwalls mit einer sichtbaren inneren Vertiefung wiedergibt. Auf eine andere Weise wurde der Burgwall in Guhre markiert, wo die Signatur eines verdickten Kreises verwendet wurde, ähnlich wie bei den im unteren Bartschgebiet gelegenen Burgwällen in Sandewalde und Klein Beltsch (poln. Bełcz Mały). Die Antwort auf die Frage nach den Ursachen der differierenden Darstellungsweise der Burgwälle kann zweifach sein: es war die Suche nach den Methoden für die Nachbildung unterschiedlich interpretierter Geländeformen oder die mit der Zeit auf den Landkarten modifizierten Markierungsweisen der Objekte eines bestimmten Typs.

Es ist zu betonen, dass der Burgwall in Leubel als ein kreisförmiger Wall dicht hinter der Grenze des Kreises Militsch markiert wurde (ohne Beschreibung, Mappe V, Karte 18). Dieses Beispiel, ähnlich wie die Abbildungsweise des Burgwalls bei

38 In Rücksicht auf einen geringen Zeitabstand zwischen den Vermessungen von J.W. Wieland und Ch.F. von Wrede dürfte man vermuten, dass der Name Hopfenberg schon früher geläufig war. 

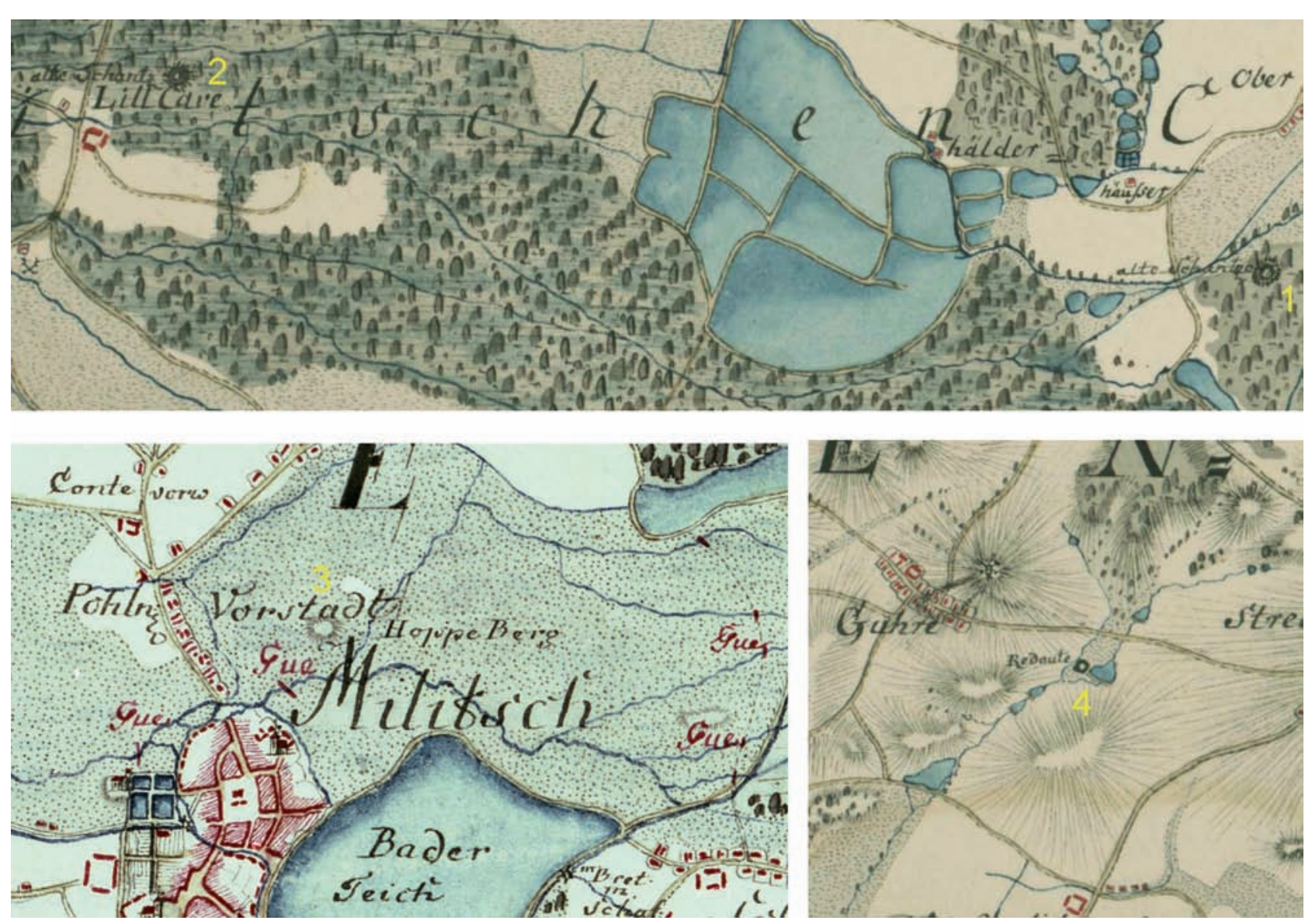

Abb. 4. Markierung der Burgwälle auf der Karte von Ch.F. Wrede. Nahaufnahme der Burgwälle in den Orten: 1 - Breslawitz, 2 - Lelikowe, 3 - Militsch, 4 - Guhre (SBB Preußischer Kulturbesitz, Sign. Karta. N 15060)

Fig. 4. Strongholds marked on the map by Ch. F. Wrede. A close-up of strongholds from the following locations:

1 - Wrocławice, 2 - Lelików, 3 - Milicz, 4 - Góry (SBB Preußischer Kulturbesitz, cat. no. Kart. N 15060)

Militsch auf der Karte von Wieland, veranschaulicht damalige Unterschiede im Erkennungsgrad der Burgwälle im westlichen und östlichen Teil des ehemaligen Kreises Militsch-Trachenberg ${ }^{39}$.

Ein weiteres Mal wurde das Bartschtal im Rahmen der Landaufnahme für das vom Generalstab beauftragte Messtischblatt kartiert. Die Arbeiten wurden 1816 angefangen und vom General Karl Friedrich Freiherr von Müffling geleitet. Die Landkarten wurden im Maßstab 1:25000 gefertigt und basierten auf der Triangulation und detaillierten

39 Weiter in der westlichen Richtung verschoben wurde die Fundstelle auf der Höhe des Ortes SandewaldeTschisteý, als Eine alte Schantze der Wall genandt markiert (Band V, Karte 12). Im Bereich des Burgwalls wurde ein rotes Rechteck aufgetragen, was verweist, dass es ein gemauertes Objekt war. Die spätmittelalterliche Besiedlung wurde in diesem Gebiet während der Ausgrabungen im Jahre 2004 belegt (Nowakowski 2008).
Vermessungsnetzen. Trotz ziemlich großer Abbildungspräzision gab es nur wenige Informationen, die für die archäologischen Studien über die Wehrsiedlungen des nordöstlichen Teils Schlesiens nützlich wären. Von den Burgwällen, die auf den älteren Karten verzeichnet worden sind, berücksichtigte man auf den Messtischblättern lediglich das Objekt in Guhre (Abb. 5:1), das mit einem Symbol markiert und als Schweden Schanze bezeichnet wurde (Urmesstischblatt 2565). Gleichzeitig ist es wichtig zu unterstreichen, dass dieses Denkmal der einzige Burgwall im Kreise Militsch-Trachenberg war, der mit einem Namen identifiziert wurde. Die Wallanlagen in Breslawitz und Lelikowe (Urmesstischblatt 2566), die auf den Karten von Wieland und Wrede vorhanden waren, kennzeichnete man nicht mehr. Hingegen wurde der Burgwall in Schmiegrode zum ersten Mal verzeichnet und mit demselben Symbol wie das Objekt in Guhre markiert (Urmesstischblatt 2635). Der Burgwall und die 

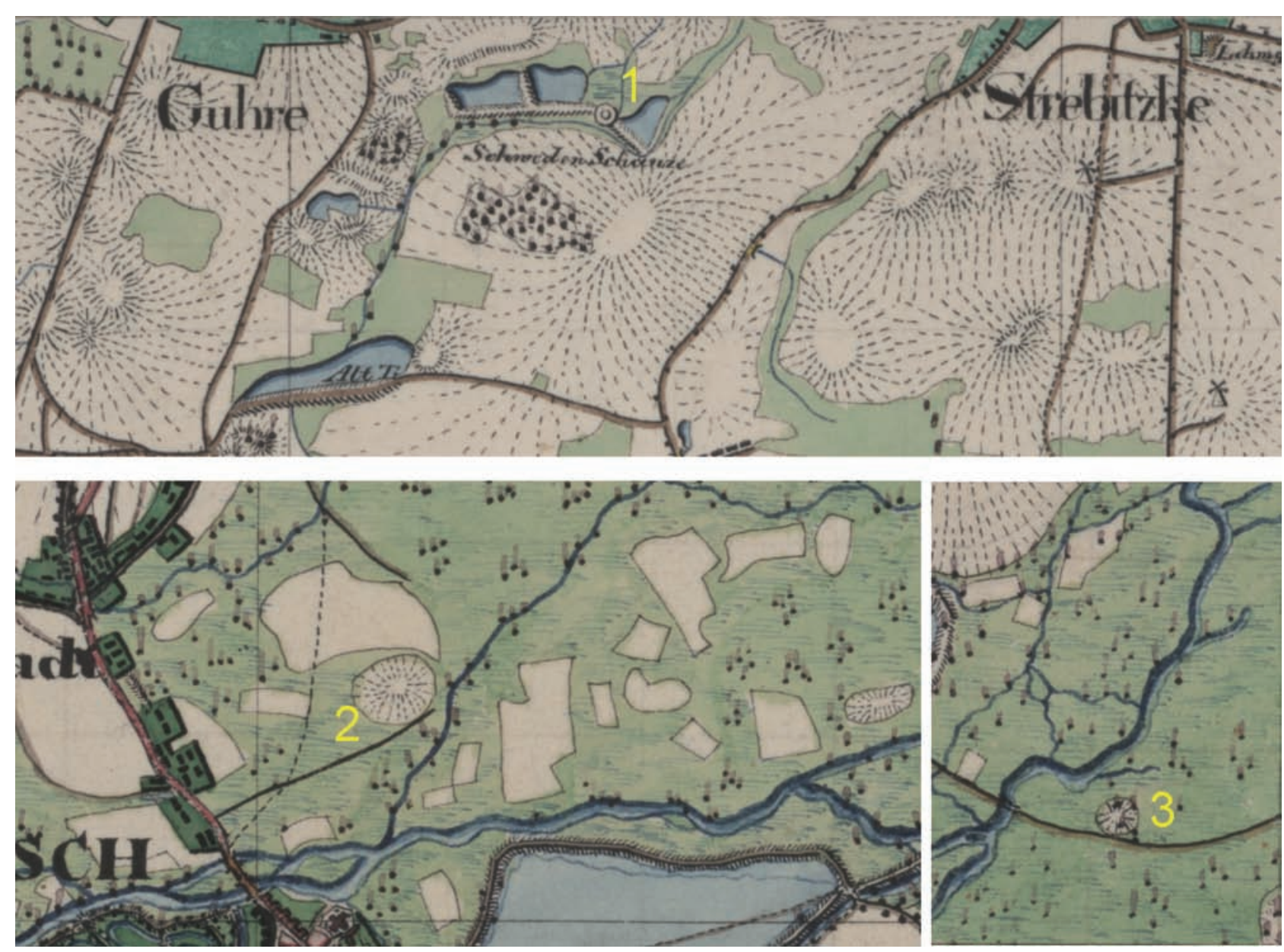

Abb. 5. Markierung der Burgwälle auf den Urmesstischblättern: 1 - Guhre, 2 - Militsch, 3 - Kasawe (SBB Preußischer Kulturbesitz, Sign. 729)

Fig. 5. Strongholds marked on the Urmestischblatt: 1 - Góry, 2 - Milicz, 3 - Kaszowo

(SBB Preußischer Kulturbesitz, cat. no. 729)

Vorburg in Militsch sind auf den Messtischblättern als natürliche Erhebungen zu sehen (Urmesstischblatt 2564), wobei ihre topographische Lage und Formen angemessen abgebildet sind (Abb. 5:2). In ähnlicher Weise stellte man auch den Burwall in Kasawe dar (Urmesstischblatt 2564, Abb. 5:3). Im Fall des Objekts in Dorf Korsenz darf man vermuten, dass eine auf der Karte inmitten nasser Wiesen berücksichtigte Baumgruppe einem ehemaligen Burgwall entspricht (Urmesstischblatt 2562). Dem Messtischblatt nach (Urmesstischblatt 2561) wurde der Wall in Kendzie den weiteren Veränderungen unterworfen: auf seinem Inneren entstand eine neue Bebauung und der bisherige Name wurde weggelassen. Die sonstigen heutzutage bekannten Burgwälle in den Dörfern Schmiegrode, Klein Ossig (Urmesstischblatt 2635) und Klein Peterwitz (Urmesstischblatt 2705), sowie Objekte in Melochwitz (Urmesstischblatt 2637) und Kraschnitz-Hammer
(Urmesstischblatt 2638), die lediglich in älterer Literatur erwähnt werden und nicht mehr vor Ort zu lokalisieren sind, wurden auf den Messtischblättern nicht bezeichnet.

Zusammenfassend kann hervorgehoben werden, dass in dem 1. Viertel des 19. Jh. neue Namen der Wallanlagen auf den Karten auftauchen, darunter Schweden- und Tatarenschanze. Einige Forscher verbinden diese Erscheinung mit einer systematischen Kartierung des Reichsgebiets, die zu dieser Zeit von den Militärkartographen durchgeführt wurde. Die neuen Namen sollten ältere herkömmliche Bezeichnungen ersetzen und dadurch eigene Überzeugungen der Kartographen zur ursprünglichen Funktion dieser Objekte zum Ausdruck bringen (Vug 1890, 9-11). Die Toponyme, die an den Aufenthalt fremder Truppen in Schlesien anknüpften, ergaben sich teilweise daraus, dass die sozusagen naturgemäß wehrhaften Orte, darunter 
vorgeschichtlichen Wallanlagen, während der neuzeitlichen Kriege als Stationierungsorte der Militäreinheiten gewählt wurden. Auf der topographischen Karte aus dem Jahr 1888 erhielt der Burgwall in Guhre den Namen Schwedenschanze, der damals als ein schmaler Wall mit ringförmigem Umriss dargestellt wurde (Topographische Karte Meßtischblatt 4470; Gr. Tschunkawe, 1888).

Gleichzeitig mit der Verbreitung der Namensgebung, welche die militärische Funktion der Wälle hervorbrachte sowie ihre Anknüpfung an die Kriege, die Schlesien seit dem Spätmittelalter heimgesucht hatten, wuchs das Bewusstsein der Forscher, dass jene Namen den tatsächlichen Charakter dieser Objekte nicht widerspiegeln können. Man begann zu spüren, dass ihre Form einer Wehrfunktion in der Zeit, als unterschiedliche Schusswaffen in herkömmlichem Gebrauch waren, nicht entsprach sowie dass diese Namen auch dort vorkamen, wo die Truppen, nach denen sie benannt wurden, nie verweilten (z. B. Schwedenschanze als Bezeichnung für die Fundstelle Breslau-Oswitz). Immer mehr Anhänger gewann die durch die ab dem Beginn des Jahrhunderts in der Lausitz geführten Untersuchungen inspirierte Ansicht (Rösch 1805; Cotta 1839; Schiffner 1840; Preusker 1830, Mosch 1855), dass die Entstehung derartiger Bauten auf die vorchristliche Zeit zurückzuführen und mit der dieses Gebiet im ersten Jahrtausend unserer Zeitrechnung oder früher bewohnenden Bevölkerung zu verbinden sei (Jaekel 1857, 57).

Wie oben schon angesprochen wurde, ist die zweite Hälfte des 19. Jh. die Zeit als die Problematik der Burgwälle - deren Ursprung, Funktion und Entstehungszeit - zum Interessengegenstand seitens der Liebhaber von Altertümlichkeiten geworden ist. Die erste thematische Landkarte, auf der die Wehranlagen im Gebiet der Oberlausitz vor einem breiteren Vergleichshintergrund markiert wurden (dabei war auch das Gebiet der unteren Bartsch mit einbezogen worden), fand sich als Beilage in der Publikation von Schuster aus dem Jahr 1869. Auf dem im Projektanalysierten Gebiet wurden drei Objekte markiert: in Guhre, Melochwitz und Kraschnitz-Hammer. Auf dem schlesischen Boden ist die erste Landkarte mit der eingetragenen Lage der Fundstellen und Einzelfunde diejenige, die Drescher im dritten Teil seines Katalogs veröffentlicht hat (Drescher 1867-1868). Von einer besonderen Bedeutung für die Geschichte der schlesischen Altertümlichkeiten ist jedoch die Karte von J. Zim- mermann aus dem Jahr 1878, betitelt Vorgeschichtliche Karte Schlesiens, deren Quellenbasis der oben besprochene Katalog geworden ist ${ }^{40}$. Es war eine großformatige Wandkarte, für die eine topographische Verwaltungskarte im Maßstab 1:300 000 als Unterlage diente. Darauf wurden die im Katalog beinhalteten Angaben aufgetragen und mithilfe bunter Zeichen, die die Genese, Entstehungszeit, und Funktion der Fundstelle sowie darauf geborgenes Fundmaterial, dargestellt ${ }^{41}$. Die als Ringwall oder Burgberg bezeichneten Fundstellen wurden mit einem Kreis markiert, falls sie nicht bebaut waren und mit einem Kreis mit einem Punkt inmitten, falls in ihrem Bereich gemauerte Konstruktionen auftraten. J. Zimmermann verzeichnete derartige Wehranlagen z. B. in den Orten Sandewalde, Steinau (poln. Ścinawa), Lüben (poln. Lubin) oder Glogau (poln. Głogów). Es ist zu betonen, dass keiner der gegenwärtig bekannten frühmittelalterlichen Burgwälle des ehemaligen Kreises Militsch-Trachenberg, sogar der mit Ausgrabungen erkannte Burgwall in Militsch, auf dieser Karte markiert wurde. Dieses Fehlen kann entweder von der Unkenntnis von Wielands Karte zeugen, auf der die Alte Schanze in Breslawitz und Lelikowe markiert wurden, oder der Problematik der Burgwälle schlechthin.

Zehn Jahre später publizierte Behla eine Monographie, die eine Karte von Burgwällen enthielt. Aus dem Text und der Kartenanalyse ergibt sich, dass der Verfasser im Gebiet des Kreises MilitschTrachenberg die als Schwedenschanze bezeichneten Fundplätze in den Ortschaften Guhre und Melochwitz sowie den Ringwall in der Ortschaft Melochwitz kannte. Dies bedeutet, dass obwohl fast 20 Jahre seit der Publikation Schusters vergan-

40 Museum der Stadt Breslau - Abteilung: Archäologisches Museum, Archiv der Abteilung für Wissenschaftliche Dokumentation, Sign. MA/A465a. Zu diesen Zwecken wurde die bei damaligen kartographischen Bearbeitungen verwendete Kartenunterlage benutzt. Die Karte wurde im kartographischen Verlag Wilhelm Gottlieb Korn gedruckt.

41 Wie es früher verwiesen wurde, bedeutete die Idee der archäologischen Karte ein Verzeichnis von Orten einer Region mit Beschreibung dort gefundener Artefakte und einer schematischen Lage der Fundstellen und nicht eine Landkarte. Die Benutzung solcher Karten-Verzeichnisse sollte durch die Anbringung eines Zeichens, das die Art jeweiliger Fundstelle bezeichnete, am Ortsnamen erleichtert werden (Kaczmarek 1996, 40-41). In diesem Zusammenhang stellte die Karte von J. Zimmermann ein Einzelstück dar. 
gen waren, die Zahl der bekannten Burgwälle im Bartschtal nicht höher wurde.

Die im 19. Jh. verfassten Abhandlungen waren nicht fehlerfrei. Dies wird am Beispiel des Burgbergs in Fürstenau belegt. Die Ortschaft ist auf der Karte in der Gegend des heutigen Dorfs Klein Ossig im Kreis Trebnitz markiert, im Katalog hingegen im Bereich des damaligen Kreises Neumark (Behla 1888, 164) erwähnt.

Die Publikation von Behla fiel mit der nächsten im nördlichen Teil Schlesiens durchgeführten, als K arte des D eutschen Reiches bezeichneten (das sog. Messtischblatt), Landesaufnahme zusammen. Auf die ältesten Karten dieser Aufnahme wurden die meisten Wehranlagen im angesprochenen Ge- biet eingetragen und fast alle mit den Namen beschrieben (die Namen fehlen nur bei den Burgwällen in Schmiegrode und Klein Ossig). Eine Ausnahme bildet hier das völlige Übergehen des Burgwalls in Kasawe, der auch auf jüngeren Karten, darunter auf einer aus dem Jahre 1939, fehlt. Bei weiteren im Rahmen dieser Landesaufnahme vollzogenen Aktualisierungen wurde den Eigennamen wie Schwedische Schanzen, Rundwälle, Burgberge u.ä. die Abkürzung K.D. - Kulturgeschichtliches D enkmal hinzugefügt. Das Vorhandensein dieser Bezeichnung bei späteren Aktualisierungen weist auf die Zeit hin, in der die Erkennung der wirklichen Art des Objekts erfolgte.

\section{MAX HELLMICH UND SYSTEMATISCHE UNTERSUCHUNGEN DER BURGWÄLLE}

Der Anfang des 20. Jahrhunderts bringt eine Institutionalisierung der Untersuchungen und Pflege des vorgeschichtlichen Erbes. Man wird sich der Tatsache bewusst, dass die bisherigen, auf die Aktivitäten der Privatpersonen und Vereine gestützten Handlungen für die Sicherstellung des letztgenannten nicht ausreichend sind. Dies fällt jedoch mit der in der deutschen Forschung zunehmenden Neigung zusammen, die vorgeschichtlichen Vorgänge im ethnischen Kontext wahrzunehmen, was auch für die Dokumentationsmethoden und Interpretation der Burgwälle in Schlesien zweifellos von Bedeutung war (Gramsch 2006, 10-13, 15). Auf die schlesischen Burgwälle richtete zu dieser Zeit Hans Seger sein Interesse, ab 1892 Leiter des Breslauer Museums für Schlesische Altertümer. Dieser regte Max Hellmich, Geodäten, der sich aus Vorliebe mit der Geschichte und Denkmälern Schlesiens beschäftigte, an, die Untersuchungen der Wallanlagen zu unternehmen. Die zur Jahrhundertwende aufgenommene Zusammenarbeit beschrieb Hellmich selbst 1934 in einem Seger gewidmeten Artikel (Hellmich 1934; vgl. auch Kramarek 1971, 234 , Anm. 33). Seger und Hellmich kamen im Jahr 1897 zusammen. Hellmich wurde bei einem Besuch in Breslau von Seger durch das Museum geführt, was eine Gelegenheit für einen Meinungsaustausch war und ihre zukunftigen Kontakte vertiefte. 1901 schlug Seger Hellmich vor, alle bekannten prähistorischen Fundstellen, darunter auch Burgwälle, auf topographische Karten einzutragen. Zwei Jahre später soll die Idee aufgekommen sein, ausgewählte
Wehranlagen zu vermessen. Die auf der Fundstelle in Gustau (Gostyń, Kr. Glogau) unternommenen Versuche wiesen nach, dass das Nivelliergerät für derartige Arbeiten nicht geeignet ist. 1904 empfahl Seger Hellmich einen Apparat, den so genannten Böschungsmesser, für die Vermessung anzuwenden und in den Jahren 1906-1907 präzisierte er den Plan einer systematischen Vermessung der schlesischen Wallanlagen und deren Kartierung in der von Hellmich vorgeschlagenen Form von Höhenlinienplänen. Max Hellmich, der damals Mitarbeiter der Königlichen Generalkommission in Glogau war, bekam in den Jahren 1907-1909 insgesamt 24 Wochen Urlaub für Feldforschung und Fertigung der Dokumentation, die von der Wilhelm GremplerStiftung finanziert wurden. In dieser Zeit besuchte er alle, wie er es selbst meinte, bekannten Wehranlagen, die er auf die Landkarten aufzeichnete, beschrieb und etwa 60 von ihnen unter Anwendung des Böschungsmessers vermaß.

In der Folgezeit wurden jene Vermessungen in Form von Lageplänen bearbeitet, die dem Museum überwiesen und im Jahre 1930 im Landesdenkmalamt für vorgeschichtliche Denkmalpflege hinterlegt wurden (Hellmich 1934, 342).

Die im ersten Jahrzehnt des 20. Jh. geführten Arbeiten wiesen nach, dass die Einschränkung auf die Inventarisierung ausgewählter Funde, um typische Formen festzulegen, die dann eine Grundlage für die Klassifikation bilden könnten, für die Untersuchungen und Sicherstellung vorgeschichtlicher Wallanlagen nicht ausreichend ist und es wäre ange- 
bracht, eine komplette Dokumentation für das Gebiet der gesamten Provinz herzustellen. 1927 wurde die Arbeitsgemeinschaft zur Erforschung der nordund ostdeutschen Wall- und Wehranlagen ins Leben gerufen (Hellmich 1934, 342; Hansen, Adams 1992, 126), später unter dem Namen Burgwall-AG bekannt (Grunwald, Reichenbach 2009, 73), die bis 1934 tätig war. Da Hellmich 1928 in Ruhestand getreten war, konnte er sich in die damals geführten Arbeiten stärker engagieren. Innerhalb der fünf nachfolgen- den Jahre konnte er seine bisherige Bearbeitungen gründlich durchsehen und sie mit neuen Vermessungen ergänzen. Dadurch entstand eine komplette Dokumentation vorgeschichtlicher Wehranlagen in Schlesien, in Form von Karten, die Angaben zur Lage, Größe und den Typen der Burgwälle beinhalteten. Im Laufe dieser Arbeiten wurden unter anderem die Burgwälle an der Bartsch inventarisiert, vermessen und ihre Höhenpläne gefertigt, die jedoch bis heute nicht erhalten blieben (Demidziuk 2014, 459).

\section{GESTALTUNG DER BEGRIFFLICHKEIT BIS ZUM BEGINN DES 20. JH.}

Anregende Voraussetzungen, die sich auf Wahrnehmungs- und Verstehensweise slawischer, frühmittelalterlicher, in der gegenwärtigen Forschung als Burgwälle bezeichneter Fundstellen aus dem schlesischen Gebiet beziehen, bringt ein Überblick von Begriffen, die bis zum Beginn des 20. Jh. für deren Benennung verwendet wurden. Bis zu dieser Zeit wurde die Diskussion über ihre Form, Funktion, Entstehungszeit und ethnographischen Beziehungen vor allem im Bereich der deutschen Sprache geführt. Es wurden damals ganz unterschiedliche Begriffe verwendet, wobei einige davon von einzelnen Verfassern verschieden definiert wurden. Ein Teil von Bezeichnungen erscheint wohl nur als Sorge um den Stil der Aussage, es gibt jedoch eine Gruppe der Forscher - sowohl derjenigen, die das Interesse ausschließlich für die Region hegen, als auch derjenigen, deren Ausarbeitungen einen breiteren Umfang erfassen - die die Versuche einer systematischen Typologie derartiger Objekte unternehmen.

Es wird angenommen, dass das Äquivalent für den polnischen Begriff grodzisko der deutsche Burgwall ist (vgl. z. B. Brather 2006, 40). Dieses Wort ist bereits aus den mittelalterlichen Quellen bekannt und für dessen Umformungen werden u.a. solche Eigennamen wie - vorwiegend im nördlichen Teil Europas vorkommende - Borchwall, Borchel und Borchelt gehalten (Behla 1888, 4; z. B. Luckau-Freesdorfer Borchelt). Die Forscher sind der Meinung, dass diese Bezeichnung im Mittelalter im umgangssprachlichen Umlauf vorhanden gewesen wäre und sich auf verlassene und ruinierte Burgen bezog, ohne Rücksicht auf die ursprüngliche Konstruktion derer Befestigungen. Im Zusammenhang mit deren Etymologie wird auf eine Möglichkeit hingewiesen, dass sich hierbei zwei Wörter von unterschiedlicher Bedeutung aber ähnlichem Klang miteinander überlappt haben: das lateinische vallum, das Holz-Erde-Befestigungen bedeutet, und das mittelhochdeutsche wuol, das eine Seuche, Verderben bezeichnet. Der deutsche Begriff Wall in Sinngehalt von einem Wehrbau aus Holz und Erde verbreitet sich erst in der Neuzeit und drückt die Wende zur antiken Bedeutungstradition aus. Die Tatsache, die diesen Vorgang vielleicht begünstigte, könnte die Errichtung von neuen Befestigungsformen gewesen sein, die mit der Entwicklung der Feuerwaffen verbunden waren und einen zusätzlichen, um die Stadtmauer herum angelegten Ring der Stadtabwehr bildeten. Die Bedeutungsrelation zwischen den Bezeichnungen Burg und Burgwall analysierte Paul Grimm. Dieser verlangte, gemäß dem mittelalterlichen Sinn dieses Begriffs, das Wort Burgwall lediglich auf die ruinierten Bauwerke zu beziehen, ohne die Kategorien einer formalen Klassifikation zu betrachten, sondern nur auf dessen Erhaltungsstand einzugehen (vgl. Biermann, Gebuhr 2008, 167-176). Seit dem 19. Jh. wird der Begriff Burgwall breiter verwendet, sein Bedeutungsbereich scheint jedoch zu fluktuieren. Bislang interpretieren einzelne Forscher - falls sie sich entscheiden, ihn zu verwenden - seinen Bedeutungsbereich ein wenig andersartig, indem sie entweder konstruktions-formale (Brather 2006) oder ethnische Aspekte hervorheben (Grunwald 2003, 8-9).

Die Burgwälle, die in Schlesien am frühestens - also an der Wende zum 19. Jh. - das Interesse der Altertumsliebhaber geweckt hatten, waren jedoch Bauwerke, die als die Burgen oder die Alten Schlößer bezeichnet wurden und innerhalb deren außer den Umwallungen auch Überreste von gemauerten Bauten erhalten blieben (Worbs 1821). Allmählich, unter dem Einfluss der Forschungen im Nachbar- 
land Lausitz, wurden Erkenntnisgegenstand auch Konstruktionen, deren grundsätzlicher und manchmal der einzige Bestandteil eine Erdaufschüttung war. Die Anregungen für die aufzunehmenden Untersuchungen kamen in der Regel aus dem Bereich der Toponomastik. Erwägungsgegenstand wurden diejenigen Landschaftsformen, deren Eigennamen ihren Wehrcharakter nahe legten. Unter den topographischen Namen, die traditionell mit den Wehrfunktionen in Verbindung gebracht wurden, sind vor allem die Schanze beziehungsweise Schwedenschanze zu nennen, aber auch solche geographische Eigennamen wie der alte Wall, das alte Schloß, der alte SchloßBberg, Burgberg und Burgsberg, die Tatarenschanze. Pandurenschanze, der Hunteberg. J anusberg, Toepferberg, Fuchsberg, Breite Berg, Ring, Moenchswall, das Meilbergel, Grodzisko, Grodek oder Grodzie (Drescher 1867-1868, 94; Behla 1888, 3-4). Das Bewusstsein, dass die Mehrheit dieser Bezeichnungen den tatsächlichen Ursprung sowie die Funktion der Objekte, auf die sie sich beziehen, nicht widerspiegeln können, kam jedoch allmählich auf. Man wurde sich allmählich dessen bewusst, dass die Vorstellungen vom Charakter der uralten Wallanlagen sich vielmals mit späteren Ereignissen überlappten und die sich darum rankenden Überlieferungen und Legenden spiegelten die Assoziationen mit den dem Gedächtnis der Einwohner näheren hussitischen oder schwedischen Kriegen, mit dem religiösen Kultus oder sogar der Räuberei wider. Behla, indem er sich auf solche traditionellen Namen in seiner Monographie der Wallanlagen in den östlichen Reichsgebieten bezieht, beschreibt das Schwinden der Erinnerung an ihre ursprüngliche Bedeutung in den lokalen Gemeinschaften folgendermaßen: Viele J ahrhunderte sind seit ihrer Errichtung und Benutzung dahingegangen, ein Volk ist nach dem anderen gefolgt, ein Geschlecht dem anderen; und den Nachkommen ist das Verständnis für diese Bauten ganz verloren gegangen (Behla 1888, 1-2). Eine interessante Spur für die tatsächliche Anwendung der Bezeichnung Burgwall taucht bei Bella im Zusammenhang mit den Wällen bei Schlieben in der Lausitz auf, den er selbst als ein Rundwall klassifiziert, indem er den Begriff Burgwall als dessen umgangssprachliche Bezeichnung anführt (im Volksmund "Burgwall" genannt, Behla 1888, 159).

Bei den meisten genannten Namen erscheint somit der Aspekt einer Schanze, eines Walls oder einer Umzäunung, unabhängig davon, ob sie in der germanischen oder slawischen Sprachtradition angesiedelt sind. Nach der Meinung von Behla ist die Namensgebung aufgrund der slawischen Sprache einheitlicher und leitet sich vom Morphem gród oder hrad ab, der sich auf ein abgegrenztes Areal bezieht. Der Ansicht dieses Forschers nach ist auch dies beachtenswert, dass die gleichlautenden $\mathrm{Na}-$ men der Wallanlagen sehr oft in den weit entfernten Gebieten auftreten (Behla 1888, 3-5). Nach Oscar Vug hingegen sind die Namen wie Schweden- oder Tatarenschanze relativ neu und kamen erst im 19. Jh. auf, als eine systematische Kartierung des Deutschen Reichs eingeleitet wurde, und dabei wurden die älteren Bezeichnungen von herkömmlichem Charakter entsetzt (Vug 1890, 9-11). In Anknüpfung an die Ortsnamen betitelt Jaekel seinen Bericht aus dem Jahr $1857 \mathrm{U}$ eber dieSchwedenschanzen, bei der Präsentation seines Interessengegenstands spricht er lieber über die Erdwälle, Ringwälle und Rundbauten (Jaekel 1857, 57). Er scheint auch der erste Verfasser zu sein, der einen Versuch unternimmt, die für die Wallanlagen in Schlesien verwendeten Begriffe zu ordnen. Von den Untersuchungen in anderen Regionen inspiriert bemerkt er, dass der in Bezug auf die schlesischen Wallanlagen am häufigsten gebräuchliche Name Schwedenschanze, der tatsächlichen Form, Funktion und Entstehungszeit dieser Objekte nicht adäquat ist. Indem Jaekel mit der Ansicht übereinstimmt, dass die Errichtung solcher Bauten in die vorchristlichen Zeiten zu setzen ist, spricht er sich für die Anwendung der in der Literatur vorhandenen Bezeichnungen Heidenwälle oder Heidenschanzen aus (Jaekel 1857, 57).

Die Burgwälle wurden in die erste umfassende Bearbeitung der schlesischen Denkmäler der vorchristlichen Zeiten - dem Katalog von Drescher - aufgenommen. Dieser Forscher unterschied die Objekte, innerhalb deren Relikte der gemauerten Bebauung erhalten blieben, von strikte Erdbauten. Er nahm dabei an, dass die uralten slawischen Holzburgen schon im Mittelalter von Massivbauten, den Burgen, ersetzt werden konnten und ein Beispiel dafür dürften die Objekte in Ritschen und Sandewalde sein. Nachdem die hölzernen Bauteile verschwunden waren, blieben dann als einzige Spuren von bestehenden Holz-Erd-Bauten die Ringwälle, innerhalb deren Einzelfunde anzutreffen waren (Drescher 1867-1868, 94). Drescher zählte 78 schlesische Fundstellen auf, die er als die nachweisbaren ehemaligen Burgplätze der heidnischen Slawen identifizierte, ohne jedoch die Bautechnik 
der Bauten näher zu beschreiben. In der Frage der ethnischen Abstammung der Burgen erkannte er somit den Zusammenhang zwischen deren Errichtung und dem Vorhandensein der Slawen in Schlesien. In seinem Verzeichnis beschränkte er sich auf die Bezeichnung der Wallform, jedoch um sie auszugliedern, bediente er sich traditioneller Namen, z. B. die Objekte in Melochwitz und KraschnitzHammer führte er als heidnische Ringwälle, gen. Schwedenschanzen an (Drescher 1867-1868, Kat.Nr. 364, 365).

Beinahe gleichzeitig mit der Publikation Dreschers erschien die Bearbeitung von Major Schuster unter dem Titel Die alten Heidenschanzen Deutschlands mit specieller Beschreibung des Oberlausitzer Schanzensystems (Schuster 1869). Der Verfasser konzentriert sich ausschließlich auf die Wehrbauten, die er für vorchristliche hält, sein Interessengebiet ist jedoch überregional. In der Einleitung zu seinem Buch bietet er ihre Klassifikation an, indem er vor allem zwei Baugruppen unterscheidet: Erdbauten und Steinbauten, und im Bereich der erstgenannten: 1) ringförmige und ovale Wälle (Ring- und Rundwälle), wobei die Ringwälle in der Regel geschlossen waren, während die ovalen auf dem Grundriss eines Abschnitts der ähnlichen Figur entstehen konnten; eine besondere Form solcher Bauten waren kegelförmige Wälle (Spitzwälle) sowie lokal vorkommende Wallanlagen auf einem quadratähnlichen Grundriss; 2) längliche Wälle (Langwälle). Die Grundrisse der Steinbauten wären unregelmäßig und von dem Geländerelief abhängig. Trotz der in der Einleitung zu seiner Bearbeitung vorgestellten Typologie bedient sich Schuster für den Fundstellenkatalog der traditionellen Namen von verzeichneten Orten, indem er bei Guhre und Kraschnitz-Hammer über die Schwedenschanzen schreibt und bei Melochwitz über die Schwedenschanzen, deren Bestandteil ein Ringwall ist (Schuster 1869, 100).

Eine andere Typologie der vorgeschichtlichen Funde nimmt J. Zimmermann (1876, 89-93) für seine Inventarisierung vor. Er sondert drei Typen der Fundstellen aus: alte Orte, heidnische Gräber und vereinzelte $F$ unde. Der erste Typ wird dann in vier Untergruppen gegliedert: heidnische $0 p$ ferstätten, Leichenverbrennungsplätze, Steinkonstruktionen (Steinkessel, Steinsitze, Nischen und Steingebilde) sowie eine Gruppe, die Ringwälle, Burgberge, Schanzen, Ruinen und dergleichen enthält (Zimmermann 1876, 89-93). In der Zeichener- klärung für die damals gefertigte Karte detailliert er diese Gliederung, indem er in der letztgenannten Gruppe die Objekte mit erhaltenen Mauerfragmenten (hier: Melochwitz) und ohne sie (KraschnitzHammer) unterscheidet.

In den Veröffentlichungen den letzten Jahrzehnten des 19. Jh. wurden etliche Versuche unternommen, frühere Erwägungen zusammenzufassen und in Ordnung zu bringen. 1888 nahm Behla die Typologie nach den Formen von Drescher prinzipiell an, er schlug allerdings gleichzeitig vor, die Burgwälle nach ihrer Größe, Lage und Baustoff zu ordnen, indem er im letztgenannten Fall Erd-, Stein- und Steinwälle mit Verkleidung mit gebranntem Lehm aussonderte (verschlackten Steinwälle, Behla 1888, 11). In der zwei Jahre später veröffentlichten Bearbeitung scheint O. Vug (1890) die Bezeichnung die Schanze zu bevorzugen. Dies hängt wohl mit seiner Ansicht über deren ursprüngliche Funktionen zusammen, die er vor allem als Wehrfunktion definiert. Allerdings verwendet er hierbei die Bezeichnung Erdwälle, die zur Aussonderung der Objekte ohne gemauerte Elemente dient. Während er in der Einleitung die Objekte kennzeichnet, die Gegenstand seines Interesses geworden sind, verwendet er, um die Umwallungen zum Schutz von Dörfern zu nennen, auch den Begriff Wallburg (Vug 1890, 7). Die die Schanzen klassifizierenden Termini, die dieser Forscher von Peukert übernimmt (Vug 1890, 20), ergeben sich vor allem aus einer Analyse ihrer Form. O. Vug unterscheidet somit:

- Spitzwälle, d.i. aus Erde aufgeschüttete Wälle, deren Durchmesser in der Krone keine $20 \mathrm{~m}$ überschreitet, und denen z. B. die sogenannten Fuchsenberge und Kuppitzen zugerechnet werden sollen,

- Rundwälle, d.i. alle Schanzen, die aus einem Wall oder einem Wall mit zugehörigem Graben bestehen, die eine Fläche von einem Durchmesser über $20 \mathrm{~m}$ einnehmen und einen kreisoder ovalförmigen Grundriss aufweisen, - Langwälle, d.i. Gräben und Grenzwälle, - Ringwälle, d.i. Wallanlagen, die aus mehr als einem Wall oder Graben bestehen und zwischen denen, in der Regel auf einer Erhöhung, eine Schanze liegt,

- Winkelschanzen - aus zwei Abschnitten bestehende Umwallungen, die unter einem Winkel aufgestellt sind, - die scharfen Vierecke - Wallanlagen über einem rechteckigen Grundriss. 
Die viereckigen Schanzen mit abgerundeten Ecken (Halbrunderschanzen) werden von ihm der Kategorie der Rund- oder Ringwälle zugewiesen.

Der Erkenntnisstand zu Burgwällen in Schlesien wird auch von Söhnel (1896) zusammengefasst. Obwohl der Verfasser den Begriff Burgwall in den Titel einführte, im Text stets die sogenannten Burgwallakten nennt und die auftauchenden Fragen als Burgwallforschung bezeichnet, verwendet er das Wort Burgwall in seinen Ausführungen nur selten, indem er es meistens mit den sich unmittelbar auf die Bauform beziehenden Begriffen Rundwall, Ringwall oder allgemein Wall ersetzt und mitunter auch mit traditionellen Schanzen. Es ist jedoch anzunehmen, dass der Forscher alle derartigen Objekte der gemeinsamen Gruppe Burgwälle zurechnet.

Das Wort Burgwall wird zum Grundbegriff in der 1906 von Mertins veröffentlichten Bearbeitung, die allgemein als eine das Wissen über die vorgeschichtlichen Funde der Region popularisierende Publikation gilt. Mertins bespricht die Burgen im Kapitel über die in Schlesien ansässigen Slawen und Polen (Mertins 1906, 126 ff.). Er hält die Burgen vor allem für Wehranlagen, obgleich er zugibt, dass die Forschung mit manchen davon auch die Kultfunktionen in Verbindung bringt. Seiner Meinung nach sind die Bezeichnungen wie Ringwall, Burgwall, Wallburg oder Schloßberg ein Versuch, sich auf die Form oder Funktion des Bauwerks zu beziehen. Als ein besonderer Burgentyp zeichnet Mertins Sumpfburgen aus, die, in sumpfigen Gebieten errichtet, dafür spezielle Pfahlkonstruktionen benötigten.

Obgleich Mertins über Burgwälle schreibt, erwähnt er auch ähnliche Bauten in anderen Teilen Europas - England, Norwegen und Finnland - es ist jedoch nicht selbstverständlich, ob er sie in den Bereich dieses Begriffs einfügen würde. In diesem Zusammenhang scheint eine Feststellung interessant zu sein, dass Hellmich diesen Begriff bei der in derselben Zeit geführten Bestandsaufnahme der schlesischen Burgwälle überhaupt nicht verwendet. Er bleibt bei formbezogenen Bezeichnungen, scheint aber nicht ihren semantischen Bereich auf die von Vug vorgeschlagenen Definitionen abzustimmen (vgl. Demidziuk 2014, Abb. 2, 4; Typologie - siehe S. 454). Eine solche typologische Erfassung konnte davon beeinflusst werden, dass dieser Forscher die schlesischen Wälle als germanische Befestigungen gegen die Slawen gedeutet hatte (Kramarek 1971, 234 f.) und ethnische Konnotationen, die den Begriff Burgwall begleiten könnten, vermeiden wollte. Allerdings sprach Hellmich, als er 1934 seine Tätigkeit bei der Vermessung und Katalogisierung der Burgwälle zusammenfasste, über Wehranlagen, Wälle und Burgwälle (Hellmich 1934, passim).

Zusammenfassend sollte auf einige Tendenzen hingewiesen werden, die im 19. und zu Beginn des 20. Jh. in der Literatur zur vorgeschichtlichen Besiedlung Schlesiens vorhanden zu sein scheinen. Es werden damals gern und vielfach, obwohl nicht immer konsequent, in der Fachliteratur Begriffe verwendet, die aufgrund der Form des Bauwerks dessen Grundriss (Ringwall, Rundwall, Langwall, die Winkelschanzen u.ä.) oder Gestalt (Wall, Spitzwall) wie auch Stoff und Konstruktion (Erdwall, Steinwall, Stumpfburg) - verstanden werden, also aufgrund Kriterien, die grundsätzlich keine Zweifel auf der Ebene der Bestandsaufnahme hegen lassen. Viel vorsichtiger geht man mit solchen Bezeichnungen wie Wallburg oder Burgwall um, vielleicht in Rücksicht darauf, dass sie gewisse Aspekte der ethnischen Abstammung oder Funktion der Wälle aufweisen, die bisher eine offene Frage in der Forschung bleiben und in bestimmten Geschichtsperioden sogar in die aktuelle politische Lage verwickelt sind (Brather 2001, 726-727; Reichenbach 2007, passim; Grunwald, Reichenbach 2009, passim; Grunwald 2009, 249-251).

\section{SCHLUSSFOLGERUNGEN}

Die Anfänge des Interesses für früheste Geschichte Schlesiens fallen mit ähnlichen Erscheinungen in Europa zusammen. Die ältesten Überlieferungen über die im ausgehenden 14. Jh. geführten „Ausgrabungen“ in dieser Region beziehen sich auf den Burgwall in Ritschen. Sie wurden jedoch nicht aufgrund des historischen Interesses unternommen, wie es z. B. in Großpolen erfolgt war (Abramowicz 1983, 30-31), sondern um nach den Gebeinen also Reliquien von Bischöfen zu suchen, die in der Zeit der Unruhen in Schmograu (poln. Smogorzewo) bei Ritschen sich hätten befinden sollen (Abramowicz 1983, 24-26). Die Entdeckungen, die wir gegenwärtig als archäologisch bezeichnen, fangen an 
sich mit der Faszination für die griechisch-römische Antike, die in den Kreisen italienischer Humanisten aufkommt zu mehren. Zu dieser Zeit lenkt sich die Aufmerksamkeit schlesischer Liebhaber für Altertümer auf Objekte der Sepulkralkultur (Abramowicz 1983). Damals wurden auch erste Entdeckungen in der Gegend von Militsch gemacht. Wir kennen zwar das Datum nicht, als die dort geborgenen Funde an die Bibliothek an der St. Maria-MagdalenenKirche zu Breslau angelangt sind, wir wissen sogar nicht, wie das erfolgt ist. Das Vorhandensein dieser Artefakte in den Breslauer Sammlungen sowie Vermerke darüber in unterschiedlichen Schriften belegen jedoch in gewisser Art und Weise das Bewusstsein für deren historischer Bedeutung. Es ist hingegen bezeichnend, dass sie keine Anregung für die Unternehmung weitläufiger Grabungsarbeiten geworden waren, wie es im Fall von Massel (poln. Masłów) war, und auch nicht so reichliche Literatur zur Folge hatten. Wenn wir nach der Ursache solches Sachverhaltes suchen würden, könnten wir auf einige Gründe verweisen, darunter auf den Mangel an Personen in der lokalen Gemeinschaft, die an den Entdeckungen solcher Art interessiert waren, da zu dieser Zeit das Geschick der archäologischen Funde, darin zu unternehmende Ausgrabungen, in hohem $\mathrm{Maß}$ vom persönlichen Interesse abhing. Fehlende Mitteilungen von eventuellen historischen Funden, die bei der Anlage des Gartens auf dem Burgwall in Kendzie mit Sicherheit zutage kommen mussten, scheint diese These zu bestätigen.

Die ersten Anzeichen für das Interesse an $\mathrm{Ob}-$ jekten, die im Gelände ablesbar waren und die gegenwärtig als Burgwälle erkannt werden, sind im ausgehenden 18. Jh. zu bemerken und man kann sie mit den sowohl auf romantische als auch auf aufklärerische Inspirationen unternommenen Untersuchungen der alten Burgen verknüpfen. In diese Strömung jener Überlegungen fügt sich die Geschichtsschreibung der linksufrigen, gotischen Burg in Militsch ein, die durch ein Missverständnis zu einem Bezugspunkt für die in Wirklichkeit sich auf die frühmittelalterliche, auf dem rechten Bartschufer gelegene Burg beziehenden Schriftquellen des 12. und 13. Jh. wird.

Zunächst erregten die Burgwälle das Interesse, innerhalb deren Überreste von gemauerten Konstruktionen zum Vorschein kamen - so wie die Wallanlagen in Sandewalde und Ritschen. Eine weitere Spur für die Erkennung der frühmittelalterlichen Wälle ist deren Markierung auf den Karten sowie die Identifizierung als Erhebungen von anthropogenem Charakter, was, wie es scheint, in erster Linie von den Militärkartographen stammt. Es sei zu betonen, dass für die Markierung der Hügel gleichzeitig unterschiedliche Zeichen benutzt wurden und wir sind auf der jetzigen Forschungsetappe nicht in der Lage, auf die Genese dieser Differenzierung zu deuten.

Ein günstiger Moment für die Entwicklung der Burgwallforschung in Schlesien konnte der Anfang des 19. Jh. gewesen sein. Das Forschungsinteresse erweckten damals ähnliche Bauten in der Lausitz, was die ersten ihnen gewidmeten monographischen Ausarbeitungen zum Ausdruck brachten. Dies fiel mit dem zunehmenden Interesse an Altertümlichkeiten in der Region zusammen. Zu dieser Zeit wurde die Gesellschaft für Geschichte und Altertümlichkeiten Schlesiens gegründet und deren Mitbegründer, Johann Gustav Gottlieb Büsching, forderte die Dokumentation des Kontexts archäologischer Funde. Der verfrühte Tod des Forschers vernachlässigte leider die Aktivitäten auf diesem Gebiet.

Ein erneutes Interesse an den Wehranlagen entwickelte sich erst nach der Mitte des 19. Jh. unter dem Einfluss weiterer in der Lausitz unternommener Initiativen, oder vielleicht auch im Zusammenhang mit der zu dieser Zeit allmählich fortschreitenden Verselbstständigung vorgeschichtlicher Archäologie als Forschungsdisziplin (Gramsch 2006, 6-9). Im Gebiet des Bartschtals fand eines der ersten Unternehmen statt, die sich als Ziel die Ausgrabungen derartiger Fundstellen setzten, und zwar waren es die Forschungsarbeiten auf dem Hopfenberg in Militsch. Der einige Jahre nach deren Abschluss herausgegebene Bericht bereichert jedoch nur in geringem Maß unseren heutigen Wissensstand. Aufgrund des Berichts kann man über die ursprüngliche Form des Burgwalls, seine Ausmaße und die Höhe der Wälle sowie die Zahl und Größe der Ausschachtung die Schlüsse ziehen, jedoch ohne die letzgenanten lokalisieren zu können. Ein beträchtlicher Teil des Texts bringt eine Zusammenstellung der geborgenen Funde, es fehlen dagegen völlig Beschreibungen von freigelegten Schichtfolgen. Die genannten Mängel sind unter anderen die Folge des damaligen allgemeinen Stands des Wissens über das prähistorische Erbe sowie unzureichender Kompetenzen in der Gruppe der Ausgräber des Hügels. In der Konsequenz hat der Bericht nicht so großen Wert wie die viel später gefertigten Dokumentationen, 
z. B. diese, die bei den Untersuchungen von Zantoch (poln. Santok 1932-1934) angefertigt wurde.

Erst weitere im 3. Viertel des 19. und 1. Viertel des 20. Jh. bearbeitete Kataloge und Bestandsaufnahmen der damals als vorgeschichtlich bezeichneten Funde ließen die Liste von Burgwällen allmählich erweitern. Schlesien steht schon damals in dieser Hinsicht den anderen Regionen Deutschlands nicht nach, die Erkennung frühmittelalterlicher Wehranlagen tritt jedoch in seinem nordöstlichen Teil mit bedeutender Verzögerung ein. Trotz der relativ früh unternommenen Grabungen auf der Fundstelle in Militsch wurde den frühmittelalterlichen Wehranlagen hier überwiegend erst in den 30er Jahren des 20. Jh. eine größere Beachtung geschenkt. Früher hatte man sie außer Acht gelassen, obgleich die meisten um die Mitte des 19. Jh. wohl eine dem als Hopfenberg bezeichneten Burgwall ähnliche Form aufwiesen. Überdies waren mindestens einige davon in unmittelbarer Nachbarschaft der Fischteiche gelegen, es ist demnach anzunehmen, dass sie als Hügel im Bewusstsein der Einwohner in den nahegelegenen Ortschaften vorhanden sein mussten. Eine volle Erkennung der Burgwälle brachte auch die Kartierung des Militscher Tals nicht. Sie wurden in den Katalogen von Drescher und J. Zimmermann nicht erfasst. In der 2. Hälfte des 19. Jh. wurden vereinzelte Objekte im östlichen Teil des ehemaligen Kreises Militsch-Trachenberg in allgemeine Bearbeitungen für das damalige gesamte Gebiet Deutschlands mit einbezogen, allerdings wurden dabei fehlerhafte Angaben wiederholt und festgehalten, insbesondere in Bezug auf die Lage der Fundstellen. Erst die Tätigkeit von Joseph Gottschalk, einem Geistlichen und Historiker, Mitglied des Vereins für Geschichte Schlesiens, der besonders an der Geschichte des Kreises Militsch interessiert war, ließ viele Ermittlungen verifizieren (Gottschalk 1928b; 1929). Unter anderen weist er als erster darauf hin, dass das linksufrige Schloss in Militsch fälschlicherweise mit dem im 12. und 13. Jh. vermerkten Bauwerk gleichgesetzt wurde.

Bis in das erste Viertel des 20. Jh. werden die sich auf die heidnischen Wälle in Schlesien bezie- henden Bezeichnungen in den deutschsprachigen Bearbeitungen unkonsequent verwendet. Der Begriff Burgwall wird zu dieser Zeit verhältnismäBig selten eingesetzt, er wird auch nicht eindeutig definiert. Die Forscher greifen zu den Begriffen, deren Inhalt auf die Form oder Konstruktion der Wälle zurückzuführen ist, sie verwenden sie ja eher intuitiv, was als Anzeichen für Zweifel an die Funktion und den Ursprung dieser Objekte zu deuten ist. Die von einigen von ihnen unternommenen Versuche, die Wallanlagen zu klassifizieren (Schuster 1869, 4-11; Vug 1890, 20), setzen sich nicht durch.

Einen interessanten Kontext für die obigen Erwägungen bilden die für das mit Schlesien benachbarte Sachsen durchgeführten Untersuchungen (Grunwald 2004). Vorgeschichtliche Holz-ErdeBauten erweckten dort früher als in Schlesien Interesse, denn zu Beginn des 19. Jh., aber eine Reihe von Forschungsprozessen verlief in den beiden Regionen ganz ähnlich. Zunächst waren nicht so sehr Historiker an den Wallanlagen interessiert, als vielmehr Vertreter anderer Berufe - Ärzte, Offiziere oder Geodäten. Die Entwicklung der Reflexion über die Geschichte der Wälle stand mit der Gründung der Vereine der Liebhaber von Altertümlichkeiten in Verbindung. Eine Anregung für die Untersuchungen wären häufig Sagen und Legenden sowie örtliche Flurnamen gewesen. Zuletzt konzentrierte sich die wissenschaftliche Debatte auf die Funktion und Datierung der Bauwerke und was daraus folgt- ihrer ethnischen Herkunft.

Ein gewisser Hinweis für die Erklärung der Verzögerung in der Erkennung vor- und frühgeschichtlicher Wallanlagen am nordöstlichen Rand Schlesiens kann hingegen die zum Gebiet Sachsens formulierte Feststellung sein, dass die Wallanlagen im Gelände nicht so sehr von der einheimischen Bevölkerung als vielmehr von den Wanderern und Reisenden identifiziert werden konnten, die untypische Formen im besuchten Gelände entdeckt haben (Grundwald 2004). Vielleicht waren die sumpfigen Bartschufer für solche landeskundliche Spaziergänge nicht besonders günstig. 


\section{LITERATUR}

Abramowicz A. 1983. Dzieje zainteresowań starożytniczych w Polsce. Cz. 1. Od średniowiecza po czasy saskie i świt oświecenia. Wrocław-Warszawa-KrakówGdańsk-Łódź.

Affek A. 2012. Kalibracja map historycznych z zastosowaniem GIS. (In:) J. Plit (Hrsg.), Źródła kartograficzne w badaniach krajobrazu kulturowego (Prace Komisji Krajobrazu Kulturowego, 16). Sosnowiec, 48-64.

Bandurska Z. 1998. Królewskie Muzeum Sztuki i Starożytności. (In:) P. Łukaszewski (Hrsg.), Muzea sztuki w dawnym Wrocławiu. Wrocław, 27-36.

Behla R. 1888. Die vorgeschichtlichen Rundwälle im östlichen Deutschland. Mit einer prähistorischen Karte. Berlin.

Biermann F., Gebuhr R. 2008. Erdanlagen im Festungsbau. Neuzeitliche Schanzen des 16. bis 19. Jahrhunderts, besonders im südlichen Brandenburg. (In:) C. Popp, J. Stephan (Hrsg.), An Elbe und Oder. Beiträge zur brandenburgischen Landesgeschichte. Winfried Schich zum 70. G eburtstag. Einhausen, 149-269.

Brather S. 2001. Slawenbilder. „Slawische Altertumskunde“ im 19. und 20. Jahrhundert. Archeologické rozhledy $53,717-751$.

Brather S. 2006. Zwischen „Fluchtburg“ und „Herrensitz“ sozialgeschichtliche Interpretationen früh- und hochmittelalterlicher Burgwälle in Ostmitteleuropa. Archaeologia Baltica 6, 40-57.

Büsching J.G.G. 1820. Nachrichten über gefundene Urnen etc. Blätter für die gesammte schlesische Altertumskunde 1, 16-17.

Burdukiewicz J.M., Demidziuk K., Bończuk-Dawidziuk U. 2016. Profesor Büsching na Uniwersytecie Wrocławskim - początki archeologii akademickiej w Europie. (In:) M. Hałub, A. Mańko-Matysiak (Hrsg.), Ślaska Republika Uczonych. Schlesische Gelehrtenrepublik. Slezská vědecká obec 7. Dresden-Wrocław, 180-206.

Cotta B. 1839. Über gewisse ringförmige Erdwälle und andere aus Schlacken bestehende Wälle in der Oberlausitz. Neues Lausitzisches Magazin 16. 116-125.

Czechowicz B. 2008. Visus Silesiae. Treści i funkcje ideowe kartografii Ślaska XVI-XVIII wieku. Wrocław.

Demidziuk K. 1999. Archiwalia archeologiczne z terenu Wrocławia do 1945 roku. Wrocław.

Demidziuk K. 2000. Archiwalia do archeologii dawnego obszaru Kreis Glogau. Głogowskie Zeszyty Muzealne 4.

Demidziuk K. 2007. Źródła archeologiczne sprzed 1945 roku do pogranicza Śląska i Wielkopolski - Ziemia
Wschowska. Ślaskie Sprawozdania Archeologiczne 49, 381-398.

Demidziuk K. 2010. Ochrona zabytków archeologicznych na Śląsku w XIX wieku na przykładzie ośrodka wrocławskiego. Silesia Antiqua 46, 201-217.

Demidziuk K. 2014. Kartoteka grodzisk śląskich Maxa Hellmicha. (In:) K. Chrzan, K. Czapla, S. Moździoch (Hrsg.), Funkcje grodów w państwach wczesnośredniowiecznej Europy Środkowej. Społeczeństwo, gospodarka, ideologia. Wrocław-Głogów, 443-464.

Drescher R. 1867-1868. Über den gegenwärtigen Stand der Ermittelungen auf dem Gebiet des schlesischen Heidenthums. Zur Kenntniss der Fundstätten von heidnischen Alterthümern in Schlesien. Schlesiens Vorzeit in Bild und Schrift 1, 4-8, 24-42, 72-81, 85-97.

Dzieduszycka B. 1977. Ze studiów nad wczesnośredniowiecznymi technikami budownictwa obronnego. Umocnienia wczesnośredniowiecznego Kaszowa w województwie wrocławskim. Slavia Antiqua 24, 73-118.

Dzieduszycka B. 1994. Z badań nad kształtowaniem się osadnictwa wczesnośredniowiecznego na przykładzie rejonu nadgoplańskiego, rejonu zachodnich Pałuk i regionu środkowego biegu Baryczy. Slavia Antiqua $35,69-99$.

Dzieduszycki W. 1972. Ceramika z wczesnośredniowiecznego Kaszowa w pow. milickim. Archeologia Polski 17/2, 391-445.

Firszt S. 1994. Zarys dziejów archeologii legnickiej. „Urnas Liegnitienses”. Silesia Antiqua 36/37, 153-168.

Gediga B. 1995. Uwagi o archeologii pradziejowej i wczesnohistorycznej na Uniwersytecie Wrocławskim od 1811 do 1945. (In:) T. Kulak, W. Wrzesiński (Hrsg.), Studia i Materiaty z dziejów Uniwersytetu Wrocławskiego 4, 33-45.

Gottschalk J. 1928a. Zwei Burgwälle im östlichen Teile des Kreises. H eimatblätter für den K reis M ilitsch-Trachenberg 9/12.

Gottschalk J. 1928b. Der Hopfenberg bei Militsch ein slawischer Burgwall und Zugleich Standort des Kastells Militsch. Heimatblätter für den Kreis Militsch-Trachenberg 2-5.

Gottschalk J.1929. Die Besiedlung des Kreises Militsch in vor- und frühgeschichtlicher Zeit. H eimatblätter für den $\mathrm{K}$ reis $\mathrm{M}$ ilitsch-Trachenberg 5/6-7/8.

Gramsch A. 2006. Eine kurze Geschichte des archäologischen Denkens in Deutschland. (In:) S. Rieckhoff, W.-R. Teegen (Hrsg.), Leipziger online-Beiträge zur 
U r- und Frühgeschichtlichen Archäologie 19, 1-18, https://www.gko.unileipzig.de/fileadmin/user_up load/historisches_seminar/02urundfruehgeschichte/ Online_Beitraege/OnlBei19.pdf [dostęp: 29.08.2016]. Grunwald S. 2003. Zur Wechselwirkung zwischen ethnischer Deutung und archäologischer Methode am Beispiel der ur- und frühgeschichtlichen Wallanlagen in Sachsen. (In:) S. Rieckhoff, W.-R. Teegen (Hrsg.), Leipziger online-B eiträge zur U $\mathrm{r}$ - und $\mathrm{F}$ rühgeschichtlichen Archäologie 5, 1-12, www.gko.unileipzig.de/ fileadmin/user_upload/historisches_seminar/02 urundfruehgeschichte/Online_Beitraege/OnlBei02. pdf [dostęp: 29.08.2016].

Grunwald S. 2004. Tempel und Festung: Die ethnischen und funktionalen Interpretationen vor- und frühgeschichtlicher Wallanlagen in Sachsen (19. Jh.). (In:) B. Gediga, P. Wojciech (Hrsg.), Archeologia, kultura, ideologie. Biskupin-Wrocław, 199-211.

Grunwald S. 2009. „Die Aufteilung der Burgen auf die Geschichte wird eine Änderung erfahren müssen“. Zur Geschichte der Zantoch-Idee. Acta praehistorica et archaeologica 41, 249-251.

Grunwald S., Reichenbach K. 2009. „Förderung der Erkenntnis vom Wesen und Zweck der Wehranlagen“" - Zur Geschichte der archäologischen Burgwallforschung in Sachsen und Schlesien in der ersten Hälfte des 20. Jahrhunderts. (In:) S. Rieckhoff, S. Grunwald, K. Reichenbach (Hrsg.), Burgwallforschung im akademischen und öffentlichen Diskurs des 20. Jahrhunderts. Wissenschaftsgeschichtliche Tagung der P rofessur für U $\mathrm{r}$ - und $\mathrm{F}$ rühgeschichte der U niversität Leipzig, Leipzig 22.-23. J uni 2007. Leipziger onlineBeiträge zur U r- und Frühgeschichtlichen Archäologie 5, 63-95.

Gummel H. 1938. Forschungsgeschichte in Deutschland. (Die Urgeschichtsforschung und ihre historische Entwicklung in den Kulturstaaten der Erde 1), Berlin.

Hansen R., Adams W. P. (Hrsg.) 1992. Geschichtswissenschaft in Berlin im 19. und 20. Jahrhundert. Persönlichkeiten und Institutionen, Berlin.

Hellmich M. 1930. Schlesische Wehranlagen. Altschlesien 3/1, 37-47.

Hellmich M. 1934. Hans Seger und die schlesischen Wehranlagen. Altschlesien 5, 340-343.

Hermann L.D. 1711. Maslographia, oder Beschreibung des Schlesischen Massel im Oelß-Bernstädtischen $F$ ürstenthum mit seinen Schauwürdigkeiten, etc. Brieg.

Hoffmann S. 1927. Der Lustgarten bei Kendzie in Militsch und seine Umgebung. H eimatblätter für den K reis $\mathrm{M} \mathrm{i-}$ litsch-Trachenberg 10/11.
Janczak J. 1976. Zarys dziejów kartografii ślqskiej do końca XVIII wieku. Opole.

Jaekel F.W. 1857. Ueber die Schwedenschanzen. 35. J ahresbericht der Schlesischen Gesellschaft für Vaterländische Kultur, 56-60.

Jaekel F.W. 1865. Ringwälle, Steinwälle und Heidenkirchhöfe, besonders in Schlesien. Schlesische Provinzialblätter. Neue F olge 4, 65-73, 135-139.

Kaczmarek J. 1996. Organizacja badań i ochrony zabytków archeologicznych w Poznaniu 1720-1958. Poznań.

Kaczmarek J. 1997. W kręgu Wilhelma Schwartza (czyli sami swoi). (In:) M. Głosek (Hrsg.), Archeologia i starożytnicy. Studia dedykowane Profesorowi Andrzejowi Abramowiczowi w 70 rocznicę urodzin. Łódź, 87-97.

Kaletynowie M., T., Lodowski J. 1968. Grodziska wczesnośredniowieczne województwa wrocławskiego. Wrocław.

Kiarszys G. 2015. Trzy światy średniowiecza. Szczecin.

Kieseler A. 2016. Der slawische Burgwall von Kleinitz (Klenica) im nördlichen Niederschlesien. (In:) Biermann F., Kieseler A., Nowakowski D. (Hrsg.), Burg, Herrschaft und Siedlung im mittelalterlichen Niederschlesien. Bonn, 211-370.

Kluge K. 1909. Chronik der Stadt Militsch, Militsch.

Knie J.G 1845. Alphabetisch-statistisch-topographische U ebersicht der Dörfer, Flecken, Städte und andern Orte der Königl. Preuß. Provinz Schlesien. Breslau, 282.

Kokosza J. 1989. Materiały archiwalne do byłego powiatu Oleśnica. Silesia Antiqua 31, 206-238.

Kolenda J. 2008. Wczesnośredniowieczny Milicz w świetle wykopalisk. (In:) J. Kolenda (Hrsg.), M ilicz. Clavis Regni Poloniae. Gród na pograniczu. Wrocław, 9-63.

Kolenda J. 2011. Wczesnośredniowieczne osadnictwo grodowe pogranicza Śląska i Wielkopolski w świetle analiz dendrochronologicznych. (In:) M. Rębkowski, S. Rosik (Hrsg.), Populi Terre marisque. Prace poświęcone pamięci Profesora Lecha Leciejewicza. Wrocław, 41-65.

Konias A. 1995. Kartograficzny obraz Ślaska na podstawie map księstw ślaskich Jana Wolfganga Wielanda i Mateusza Schubartha z polowy XVIII wieku. Katowice.

Konias A. 2010. Kartografia topograficzna państwa i zaboru pruskiego od II polowy XVIII wieku do połowy XX wieku. Słupsk.

Kot H. 1970. Historia nowożytnej kartografii Ślaska 18001939 (poza kartografiq urzędowa). Katowice.

Kowalski I., Kozica K. 2010. Dawna D olina Baryczy. Altes Bartschtal. Milicz.

Kramarek J. 1958. Pierwsze wykopaliska archeologiczne na Śląsku. Z Otchłani Wieków 24/1, 25-33. 
Kramarek J. 1969. Z dziejów archeologii na Śląsku. Część I. Silesia Antiqua 11, 225-242.

Kramarek J. 1970. Z dziejów odkryć archeologicznych na Śląsku. Część II. Silesia Antiqua 12, 198-225.

Kramarek J. 1971. Z dziejów odkryć archeologicznych na Śląsku. Część III. Silesia Antiqua 13, 223-253.

Kramarek J. 1972. Z dziejów archeologii na Śląsku. Część IV. Silesia Antiqua 14, 207-229.

Kramarkowie I. i J. 1972. U źródet archeologii. Wrocław.

Kramarek J., Margas A. 1980. Materiaty archiwalne dotyczqce poszukiwań na Ślasku (do 1945 roku). Wroclaw.

Kurnatowska Z. 2000. Relacje Wielkopolski i Śląska w okresie plemiennym i wczesnośredniowiecznym. (In:) M. Młynarska-Kaletynowa, E. Małachowicz (Hrsg.), Ślask około roku 1000. Materiały z sesji naukowej we Wroctawiu w dniach 14-15 maja 1999 roku. Wrocław, 11-24.

Kruse F.C. 1819. Budorgis oder etwas über das alte Schlesien vor Einführung der Christlichen Religion besonders zu den Zeiten der Römer nach gefundenen Alterthümern und den Angaben der Alten, Leipzig.

Leciejewicz L. 2008. Wprowadzenie w problematykę sympozjum. (In:) J. Kolenda (Hrsg.), M ilicz. Clavis Regni Poloniae. Gród na pograniczu. Wrocław, 5-7.

Lindner K. (Hrsg.) 1987. Zwischen O der und Riesengebirge. Schlesische Karten aus fünf $\mathrm{J}$ ahrhunderten. Staatbibliothek Preussischer Kulturbesitz; Ausstellung d. Staatsbibliothek Preuss. Kulturbesitz, Berlin, [7. F ebruar - 4. April 1987; Ratingen-Hösel, Oberschles. Landesmuseum, 13. Mai - 21. Juni 1987], Weissenhorn-Bayern.

Luchs H. 1875. Verzeichnis der Austellung ganzer heidnischen Gräber. Schlesiens Vorzeit im Bild und Schrift 2, 217-221.

Łuczak A. 2015. Archiwalne mapy jako źródło w badaniach nad dawnym krajobrazem kulturowym. Wykorzystanie narzędzi GIS w ocenie kartometryczności średnioskalowych map topograficznych Śląska z XVIII i XIX wieku. Ślaskie Sprawozdania Archeologiczne 57, 271-290.

Mertins O. 1906. Wegweiser durch die U rgeschichte Schlesiens und der Nachbargebiete. Breslau.

Militscher 1857. Militscher K reisblatt 1857, 14, 115-116.

Młynarska M. 1960. Burgum milickie. Kwartalnik Historii Kultury Materialnej 8, 447-475.

Mosch K.F. 1855. Die alten heidnischen O pferstätten und Steinalter thümer des Riesengebirges. Görlitz.

Moździoch S., Przysiężna-Pizarska M. 2008. Gród Recen - refugium episcopi. (In:) J. Kolenda (Hrsg.), M ilicz.
Clavis Regni Poloniae. Gród na pograniczu. Wrocław, 235-253.

Nowakowski D. 2008. Wznowienie badań na grodzisku kasztelańskim w Sądowlu (Lechitów, stan. 4), gm. Wąsosz. (In:) J. Kolenda (Hrsg.), Milicz. Clavis Regni Poloniae. Gród na pograniczu. Wrocław, 171-211.

Paroń A. 2008. Ugoda w sprawie kasztelanii milickiej (26 VI 1249). (In:) J. Kolenda (Hrsg.), M ilicz. Clavis Regni Poloniae. Gród na pograniczu. Wrocław, 97-128.

Preusker K. 1830. Landgräben und Wälle aus der Vorzeit. Neues Lausitzisches Magazin 7, 268-271.

Reichenbach K. 2007. "Burgengeschichte ist politische Geschichte" - Burgwallforschung in Schlesien am Beispiel der Ausgrabungen in Nimptsch/Niemcza. Ślaskie Sprawozdania Archeologiczne 49, 207-224.

Rösch C.L. 1805. Von den alten Schanzen in der Oberlausitz, Neue Lausitzische M onatschrift, I 19-44, II 4647; 1807, 455.

Sadowski J. N. 1877. Wykaz zabytków przedhistorycznych na ziemiach polskich. Porzecza Warty i Baryczy. Zeszyt 1. Kraków.

Schiffner A. 1840. Beschreibung von Sachsen und der Ernestinischen, Reußischen und Schwarzburgischen Lande, Stuttgart.

Schloß 1841. Das alte Schloß zu Militsch. Silesia, oder Schlesien in historischer, romantischer $u$. malerischer Beziehung 1, 177-179, 188-189.

Schuster O. 1869. Die alten Heidenschanzen D eutschlands mit specieller Beschreibung des 0 berlausitzer Schanzensystems. Dresden.

Schwartz W. 1875-1882. Materialien zur prähistorischen Kartographie der Prov. Posen (Zusammenstellung der Funde und Fundorte) - Beilage zum Programm des Königl. Fr. Wilh. Gymnasiums in Posen.

Seger H. 1912. Maslographia 1711-1911, Schlesiens Vorzeit in Bild und Schrift. Neue Folge 6, 1-16.

Senf F. 1884. Die verschlackten Wälle in der Oberlausitz. Neues Archiv für Sächsische Geschichte und Altertumskunde 5, 1884, 227-238.

Senf F. 1892. Die verschlackten Wälle in der Oberlausitz. Uralte Kasamatten (Burgwallwohnungen). Schlesische Zeitung 514 Morgenblatt.

Söhnel H. 1896. Die Burgwälle Schlesiens nach dem gegenwärtigen Stand der Forschung. Schlesiens Vorzeit im Bild und Schrift 6/1, 89-106.

Studia 1995. Studia i Materiaty do osadnictwa Wielkopolski wczesnohistorycznej 7, Poznań-Torun.

Volkmann G.A. 1720. Silesia Subterranea, oder Schlesien mit seinen unterirdischen Schätzen (...): Seltsamheiten, welche dieses Land mit andern gemein, oder zuvoraus 
hat, als Edelen, und U nedelen, ohne und mit Figuren sich praesentirenden und seltsam gebildeten Steinen ..., $\mathrm{N}$ ebst vielen Abbildungen und Kupffern, Leipzig.

Vug O. 1890. Schlesische Heidenschanzen, ihre Erbauer und die Handelsstraßen der Alten, ein Beitrag zur deutschen Vorgeschichte; in zwei Bänden mit $118 \mathrm{Ab}$ bildungen und $1 \mathrm{~K}$ arte. Grottkau.

Virchow R. 1872. Die Dreigraebern, Schlesische Provinzialblätter. Neue F olge 9, 568.

Thebesius G. 1733, Weyland George Thebesii [...] Liegnitzische J ahr-Bücher, Worinnen so wohl die M erckwürdigkeiten dieser Stadt, Als auch die Geschichte der Piastischen Hertzoge in Schlesien von ihrem Anfange biß zum Ende des 16. Jahrhunderts [...] untersuchet [...] werden [...] / Nebst einer Vorrede, LebensBeschreibung des Verfassers und nützlichen Registern heraus gegeben von M. Gottfried Balthasar Scharffen.

Worbs J.G. 1821. Beiträge zur Geschichte der schlesischen Burgen. Schlesische P rovinzialblätter 1821, 73, 507525; 74, 293-304. 532-540; 1823, 77, 1-26.

Wytyczak R. 1998. Ślask $w$ dawnej kartografii: obraz Ślaska na mapach XVI-XVIII wieku w zbiorach Zakładu Narodowego im. Ossolińskich we Wroctawiu. Wrocław.

Wytyczak R. 2008. Ślask na mapach z lat 1800-1945 w zbiorach Zaktadu Narodowego im. Ossolińskich we Wrocławiu. Wrocław.

Zedlers Lexikon 1731-1754. Grosses vollständiges U niversal Lexicon aller Wissenschafften und Künste: Welche bißhero durch menschlichen Verstand und Witz erfunden und verbessert worden; Darinnen so wohl die Geographisch-Politische Beschreibung des E rd-Creyses, nach allen M onarchien, Käyserthümern,
... samt der natürlichen Abhandlung von dem Reich der Natur, ... Als auch eine ausführliche HistorischGenealogische Nachricht von den ... berühmtesten Geschlechtern in der Welt, ... Ingleichen von allen Staats- Kriegs- Rechts- Policey und HaußhaltungsG eschäfften des Adelichen und bürgerlichen Standes, ... Wie nicht weniger die völlige Vorstellung aller in den Kirchen-Geschichten berühmten Alt-Väter, Propheten, Apostel, Päbste, Cardinäle, ... Endlich auch ein vollkommener Inbegriff der allergelehrtesten Männer, berühmter Universitäten ... enthalten ist / [Johann Heinrich Zedler]. Nebst einer Vorrede, von der Einrichtung dieses mühsamen und grossen Wercks J oh. P et. von Ludewig, J Cti, Königl. Preußischen geheimden und Magdeburg. Regierungs- und Consistorial-Raths.

Zimmermann F.A. 1783-1796. Beyträge zur Beschreibung von Schlesien 7, Brieg.

Zimmermann J. 1874, Berichte über die im Auftrage des Vereins für das Museum Schlesischer Alterthümer ausgeführten Untersuchungen einiger Ringwälle, Schanzen und Burgberge in Mittel- und Nieder-Schlesien. Schlesiens Vorzeit in Bild und Schrift 10, 206-215

Zimmermann J. 1876. Zur Kenntniss der Fundstätten prähistorischer Alterthümär in Schlesien. Schlesiens Vorzeit in Bild und Schrift 4, 87-97.

Zachariasz M. 2012. Detekcja historycznych przemian pokrycia terenu z zastosowaniem elementów logiki rozmytej. (In:) J. Plit (Hrsg.), Źródła kartograficzne w badaniach krajobrazu kulturowego. (Prace Komisji Krajobrazu Kulturowego, 16). Sosnowiec 2012, 84-94.

Adresy Autorek:

Dr Justyna Kolenda

Ośrodek Badań nad Kulturą Późnego Antyku

i Wczesnego Średniowiecza

Instytut Archeologii i Etnologii PAN

ul. Więzienna 6

50-118 Wrocław

e-mail: jko@arch.pan.wroc.pl

\author{
Dr Agnieszka Seidel-Grzesińska \\ Instytut Historii Sztuki \\ Uniwersytetu Wrocławskiego \\ ul. Szewska 36 \\ 50-139 Wrocław \\ e-mail: agnieszka.seidel-grzesinska@uwr.edu.pl
}

